\title{
Establishing a rainfall threshold for flash flood warnings in China's mountainous areas based on a distributed hydrological model
}

\author{
Qinghua Miao ${ }^{a}$, Dawen Yang ${ }^{\mathrm{a}, *}$, Hanbo Yang ${ }^{\mathrm{a}}$, Zhe $\mathrm{Li}^{\mathrm{b}, \mathrm{c}}$ \\ a State Key Laboratory of Hydroscience and Engineering, Department of Hydraulic Engineering, Tsinghua University, Beijing 100084, China

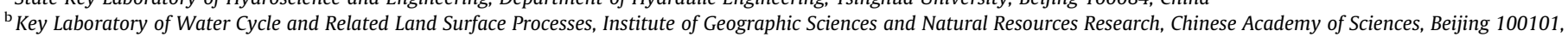 \\ China \\ ' State Key Laboratory of Severe Weather, Chinese Academy of Meteorological Sciences, Beijing 100081, China
}

\section{A R T I C L E I N F O}

\section{Article history:}

Available online 30 April 2016

This manuscript was handled by $\mathrm{K}$.

Georgakakos, Editor-in-Chief

\section{Keywords:}

Flash flood warning

Distributed hydrological model

Ungauged catchments

Rainfall threshold

Binary classification

\begin{abstract}
S U M M A R Y
Flash flooding is one of the most common natural hazards in China, particularly in mountainous areas, and usually causes heavy damage and casualties. However, the forecasting of flash flooding in mountainous regions remains challenging because of the short response time and limited monitoring capacity. This paper aims to establish a strategy for flash flood warnings in mountainous ungauged catchments across humid, semi-humid and semi-arid regions of China. First, we implement a geomorphology-based hydrological model (GBHM) in four mountainous catchments with drainage areas that ranges from 493 to $1601 \mathrm{~km}^{2}$. The results show that the GBHM can simulate flash floods appropriately in these four study catchments. We propose a method to determine the rainfall threshold for flood warning by using frequency analysis and binary classification based on long-term GBHM simulations that are forced by historical rainfall data to create a practically easy and straightforward approach for flash flood forecasting in ungauged mountainous catchments with drainage areas from tens to hundreds of square kilometers. The results show that the rainfall threshold value decreases significantly with increasing antecedent soil moisture in humid regions, while this value decreases slightly with increasing soil moisture in semihumid and semi-arid regions. We also find that accumulative rainfall over a certain time span (or rainfall over a long time span) is an appropriate threshold for flash flood warnings in humid regions because the runoff is dominated by excess saturation. However, the rainfall intensity (or rainfall over a short time span) is more suitable in semi-humid and semi-arid regions because excess infiltration dominates the runoff in these regions. We conduct a comprehensive evaluation of the rainfall threshold and find that the proposed method produces reasonably accurate flash flood warnings in the study catchments. An evaluation of the performance at uncalibrated interior points in the four gauged catchments provides results that are indicative of the expected performance at ungauged locations. We also find that insufficient historical data lengths ( 13 years with a 5 -year flood return period in this study) may introduce uncertainty in the estimation of the flood/rainfall threshold because of the small number of flood events that are used in binary classification. A data sample that contains enough flood events (10 events suggested in the present study) that exceed the threshold value is necessary to obtain acceptable results from binary classification.
\end{abstract}

(c) 2016 Elsevier B.V. All rights reserved.

\section{Introduction}

Flash floods are distinguished from regular floods by their rapid occurrence, which leaves an extremely short time for hazard warning. Flash floods can be generated quickly after heavy rainfall

\footnotetext{
* Corresponding author at: Department of Hydraulic Engineering, Tsinghua University, Room 312, New Hydraulic Engineering Building, Beijing 100084, China. Tel.: +861062796976

E-mail address: yangdw@tsinghua.edu.cn (D. Yang).
}

events, especially when highly intense rainfall occurs in steep mountainous areas with poor vegetation cover. Flash floods are usually localized disasters that occur in catchments of a few hundred square kilometers or less, with response times of a few hours or even less (Borga et al., 2007). The short lead time and small area collectively enhance the difficulty of flash flood forecasting. Flash floods are often associated with other natural hazards such as landslides and debris flows, which amplify the potential threats to human life and property. 
Flash floods occur frequently in mountainous areas in China because of frequent summer rainstorms and the complex topogeological conditions. According to statistics, 263,000 people died in flood disasters during 1950-2000, with flash floods constituting $68.4 \%$ of the deaths. This proportion increased greatly, up to $87.6 \%$, in 2010 (Zhang, 2013). Currently, more than 30,000 automated meteorological stations are active in China (Shen et al., 2013), and a number of studies have focused on quantitatively estimating the precipitation from multi-source precipitation measurements (Hou et al., 2013; Zhu et al., 2013). The current severe situation and the abundant rainfall observations and data availability make establishing a flash flood warning system over the large areas of the mountainous regions in China extremely necessary and feasible.

In practice, a flash flood warning can be issued based on realtime hydrological forecasting. Many researchers have recognized that the quantitative forecasting of flash floods is still a challenge, especially for lead times that are shorter than 1-3 h (Alfieri et al., 2012). Most real-time flood forecast systems, such as the US National Weather Service's River Forecast System (Morris, 1975), the European Flood Alert System (Alfieri et al., 2012), and the Chinese National Flood Forecasting System (Liu, 2009), are based on hydrological and/or hydraulic models and are intended to provide real-time forecasts of discharges and/or water stages at critical river sections. The hydrological models that are used in flood forecasting include lumped models and distributed models. Both types of models require hydrological data to calibrate model parameters, while catchments that urgently need flash flood forecasting are generally ungauged (i.e., no hydrological data available for calibration). Refsgaard and Knudsen (1996) found that distributed and lumped models perform similarly with calibration, but distributed models perform marginally better without calibration in study catchments with drainage areas that range in size from several hundreds to one thousand square kilometers. Javelle et al. (2010) noted that distributed hydrologic models can provide river discharges and hydrological statuses such as soil moisture over the whole catchment, which is an essential advantage for real-time flood forecasting. Younis et al. (2008) reported that the operational European Flood Alert System, which was developed for large rivers, could achieve satisfactory results in small French Mediterranean watersheds. Meanwhile, real-time forecast systems that are based on hydrological models might exhibit an increased probability of system failures because of model instability, incorrect updating procedures, and error propagation (Martina et al., 2006). Under these circumstances, an early warning method that is based on a rainfall threshold can serve as a satisfactory auxiliary reference, as proposed by several past studies (Mogil et al., 1978; Schmidt et al., 2007; Norbiato et al., 2008; Gourley et al., 2012).

The main idea of an early warning method that is based on a rainfall threshold is to determine the possibility of a disastrous flash flood occurrence solely by comparing the forecasted or observed rainfall with the rainfall threshold. A forecasted or observed rainfall amount that exceeds this rainfall threshold indicates a high possibility of a disastrous flash flood occurrence, and an alert is issued. In this approach, determining the value of the rainfall threshold is the critical step; many studies have dealt with this issue. A very simple method is based on historical data, namely, drawing a line to best separate between critical and noncritical conditions in a figure with the event duration as the abscissa and the accumulated rainfall depth as the ordinate (Cannon et al., 2008). However, this method does not consider the initial soil moisture conditions; storms and floods do not always occur at the same frequency because of different antecedent soil moisture conditions. Another notable method is Flash Flood Guidance (FFG), which was established by the US National Weather Service (NWS) in the late 1970s (Mogil et al., 1978). This system greatly improved flash flood forecasting by considering the initial soil moisture status. The US NWS's FFG method requires running a lumped hydrological model iteratively for several different hypothetical rainfall amounts over selected time spans and simulated soil moisture conditions, which are obtained from a hydrological model that records continuous soil moisture data to determine the critical rainfall that is necessary to cause a predefined discharge threshold at the outlet of the catchment. This critical rainfall, which is often considered to be uniform in space and time over a certain catchment, is often referred to as the rainfall threshold. A flood warning is issued according to the likelihood of a flash flood occurrence by comparing the observed or forecasted rainfall accumulation during a time period with this rainfall threshold. Recently, Schmidt et al. (2007) proposed a raster-based method to derive a gridded FFG (GFFG) in a distributed manner. Gourley et al. (2012) reported that FFG performs better than the GFFG, but the GFFG can detect the spatial variability.

Hydrological model parameters cannot be calibrated in ungauged catchments. A practice that is often followed is approximating model parameters from the closest gauged catchment according to the spatial proximity (Blöschl, 2005). However, the performance of rainfall threshold estimation in ungauged basins with this parameter transposition approach is not very satisfactory (Norbiato et al., 2008). The poor performance in ungauged catchments generally stems from simulation bias because the hydrological model parameters cannot be calibrated (Blöschl, 2005) and from the uncertainties in specifying the magnitude of the flooding threshold because of a lack of historical observations (Ntelekos et al., 2006). An attempt to extend the application of flood warning to ungauged catchments has been made by using the model-based runoff threshold (Reed et al., 2007), which requires running a hydrological model and conducting a frequency analysis with model-based discharges to determine the runoff threshold. This research also found that the overall performance of a distributed hydrological model decreased with decreasing catchment area. This increasing model uncertainty at small scales may obscure the benefits of high-resolution distributed models in flash flood forecasting. A comparative study (Norbiato et al., 2009) was conducted in four Italian catchments, and the results indicated that using model-based thresholds can improve flood warning method using the rainfall threshold in both gauged and ungauged catchments. On the one hand, the distributed model makes hydrological calculations at spatial and temporal scales that are more commensurate with flash flooding; on the other hand, the distributed models perform better than lumped models without calibration (Refsgaard and Knudsen, 1996). The above merits suggest that the rainfall threshold from distributed models may perform better than that from lumped models. Thus, unlike the US NWS's FFG, which regularly applies a lumped hydrological model to catchments on a scale of $1000 \mathrm{~km}^{2}$ (Gourley et al., 2012), this study takes advantage of distributed hydrological models in flood simulations at ungauged locations and uses the threshold frequency method to determine the rainfall threshold for flash flood warnings in China's mountainous areas.

The rainfall threshold value of the US NWS's FFG is usually updated one to three times per day (Gourley et al., 2012), while the GFFG is updated three to four times per day (Seo et al., 2013). This process requires the systems to frequently calculate the rainfall threshold. Despite the availability of continuous rainfall forecasts in real time, the rainfall threshold is only updated three to four times a day, which may reduce the warning accuracy when flash flood events occur on a short time scale. Another critical issue is the definition of rainfall duration. Although the US NWS's FFG suggests the use of rainfall thresholds over different time spans (for example, $1 \mathrm{~h}, 3 \mathrm{~h}$, and $6 \mathrm{~h}$ ), no discussion exists regarding selecting an appropriate duration for flash flood warnings. 
In this study, we propose an approach that uses binary classification instead of running a hydrological model iteratively to determine the rainfall threshold under different antecedent soil moisture values. To improve the warning accuracy, especially in ungauged catchments, we adopt a distributed hydrological model to simulate historical floods and use frequency analysis to determine the flooding threshold, which is then used to determine the rainfall threshold. We aim to (1) establish a strategy for flash flood warning that is based on the definition of a rainfall threshold and (2) evaluate the proposed method in gauged and ungauged catchments with various climatic conditions in China.

After the Introduction, Section 2 presents the study area and data that are used in this paper. Section 3 introduces the istributed hydrological model that is used in this study and the model validation. The method to compute the rainfall threshold for flash flood warnings is described in Section 4. Section 5 consists of the results and discussion. Finally, a brief summary and the major conclusions are provided in Section 6.

\section{Study area and data}

This study selected four catchments in different climate regions to establish a strategy for flash flood warning in China. The study areas included the Suichuan catchment (with a drainage area of $910 \mathrm{~km}^{2}$ and mean annual rainfall of $1637 \mathrm{~mm}$ ) of the Ganjiang River, which is located in a humid region with an annual rainfall value that is greater than $800 \mathrm{~mm}$; the Maduwang catchment (with a drainage area of $1601 \mathrm{~km}^{2}$ and mean annual rainfall of $735 \mathrm{~mm}$ ) of the Ba River, which is located in a semi-humid region with an annual rainfall value that ranges from $400 \mathrm{~mm}$ to $800 \mathrm{~mm}$; the Banqiao catchment (with a drainage area of $493 \mathrm{~km}^{2}$ and mean annual rainfall of $670 \mathrm{~mm}$ ) of the Banqiao River, which is also located in a semi-humid region; and the Zhidan catchment (with a drainage area of $774 \mathrm{~km}^{2}$ and mean annual rainfall of $414 \mathrm{~mm}$ ) of the Zhou River, which is located in a semi-arid region with an annual rainfall value that ranges from $200 \mathrm{~mm}$ to $400 \mathrm{~mm}$. The concentration times (i.e., the time for water to flow from the most remote point in a watershed to the watershed outlet) were approximately 7, 9, 4 and 6 h for the Suichuan catchment, Maduwang catchment, Banqiao catchment and Zhidan catchment, respectively. Fig. 1 shows the locations of the four study catchments, and their basic hydroclimatic and geographical characteristics are summarized in Table 1.

The four catchments are all mountainous terrains. The Suichuan catchment is located in East China, with an elevation difference of $1458 \mathrm{~m}$. The Maduwang and Banqiao catchments are located in the northern and southern Qinling Mountains, with elevation differences of $1986 \mathrm{~m}$ and $918 \mathrm{~m}$, respectively. The Zhidan catchment is located in the Loess Plateau, with an elevation difference of $586 \mathrm{~m}$.

The hydrological characteristics vary greatly among the four catchments. The annual runoff coefficient ranges from a rather low value of approximately 0.04 in the Zhidan catchment to a relatively high value of approximately 0.55 in the Suichuan catchment. However, these regions share a seasonal rainfall pattern that is concentrated in flood seasons, with heavy rainstorms being the major cause of flash floods. However, the flood seasons of these areas are different. The Suichuan catchment has a longer flood season from April to September, while the flood seasons of the other three study catchments mainly range from June to October.

The data that were used in this study include geographical information for the catchment landscape, which were used to build the distributed hydrological model; meteorological data, which were used as an input to the hydrological model; and hydrological data, which were used to calibrate and validate the hydrological model. The catchment topography was represented by using a digital elevation model (DEM) with a spatial resolution of $90 \mathrm{~m}$, which was downloaded from the SRTM Database (http://srtm.csi.cgiar. org). The soil map was obtained from the China Dataset of Soil Properties for Land Surface Modeling (Dai et al., 2013). Land use/land cover data were obtained from the Environmental and Ecological Science Data Center of West China (http://westdc.westgis.ac. $\mathrm{cn} /)$ at a $100 \mathrm{~m}$ resolution. The gauge rainfall data and observed discharge data were collected from the Hydrological Bureau, Ministry of Water Resources of China. Daily rainfall data were available over the entire period (from 1951 to 2002 in the Suichuan catchment and from 2000 to 2010 in the other three catchments), while event-based rainfall data were available only in flood seasons, with the temporal resolution varying from $6 \mathrm{~h}$ to $1 \mathrm{~h}$ when the rainfall intensity increased. The availability and temporal resolutions of the discharge data were similar to those of the rainfall data, with daily data available over the entire period and event-based data available only in the flood season, as shown in Table 2. Daily meteorological data were obtained from the China Administration of Meteorology, including the precipitation; mean, maximum, and minimum air temperatures; sunshine duration; wind speed; and relative humidity. These meteorological data were used to estimate the potential evaporation by the Penman equation (Penman, 1948) in the hydrological model.

\section{Distributed hydrological model}

\subsection{Brief description of the distributed hydrological model}

The hydrological model that was used in this study is a distributed geomorphology-based hydrological model (GBHM) that was developed by Yang et al. (1998, 2002). The model structure is built on the catchment geomorphological properties, and the model represents the catchment's hydrological processes by using physically based equations. This model can simulate evapotranspiration, infiltration, soil moisture and runoff.

The main feature that distinguishes GBHM from other distributed models is the discretization scheme and sub-grid parameterization. For convenient utilization of the available geographical information, GBHM uses a grid system to discretize the study catchment. Considering a tradeoff between the computation efficiency and accurate landscape parameterization, GBHM uses a relatively large grid size, within which the river network can be derived appropriately from the DEM. The river network is ordered by the Horton-Strahler scheme. The study catchment is divided into a number of sub-catchments that correspond to each river segment. The grids within a sub-catchment are then grouped into several flow intervals according to the flow distance; the runoff that is generated from the grids within a flow interval contributes to the interval of the mainstream. Each grid is represented by a number of topographically similar "hillslope-valley" systems, with the hillslope being the basic unit of the hydrological simulation (Yang et al., 2002, 2015).

GBHM mainly consists of a hillslope hydrological module and a kinematic wave flow routing module (Yang et al., 2002, 2004). In the hillslope module, GBHM simulates the hydrological processes, including interception, evapotranspiration, infiltration, overland flow, unsaturated flow and groundwater flow. Evapotranspiration is calculated as the evaporation from the canopy water storage, surface storage and soil surface and transpiration from the root zone. The topsoil is divided into several layers according to their depths, and the vertical flow is described by using the Richards equation, which is solved by an implicit numerical scheme. After the surface flow is calculated, the overland flow concentration can be described by using the one-dimensional kinematic wave 

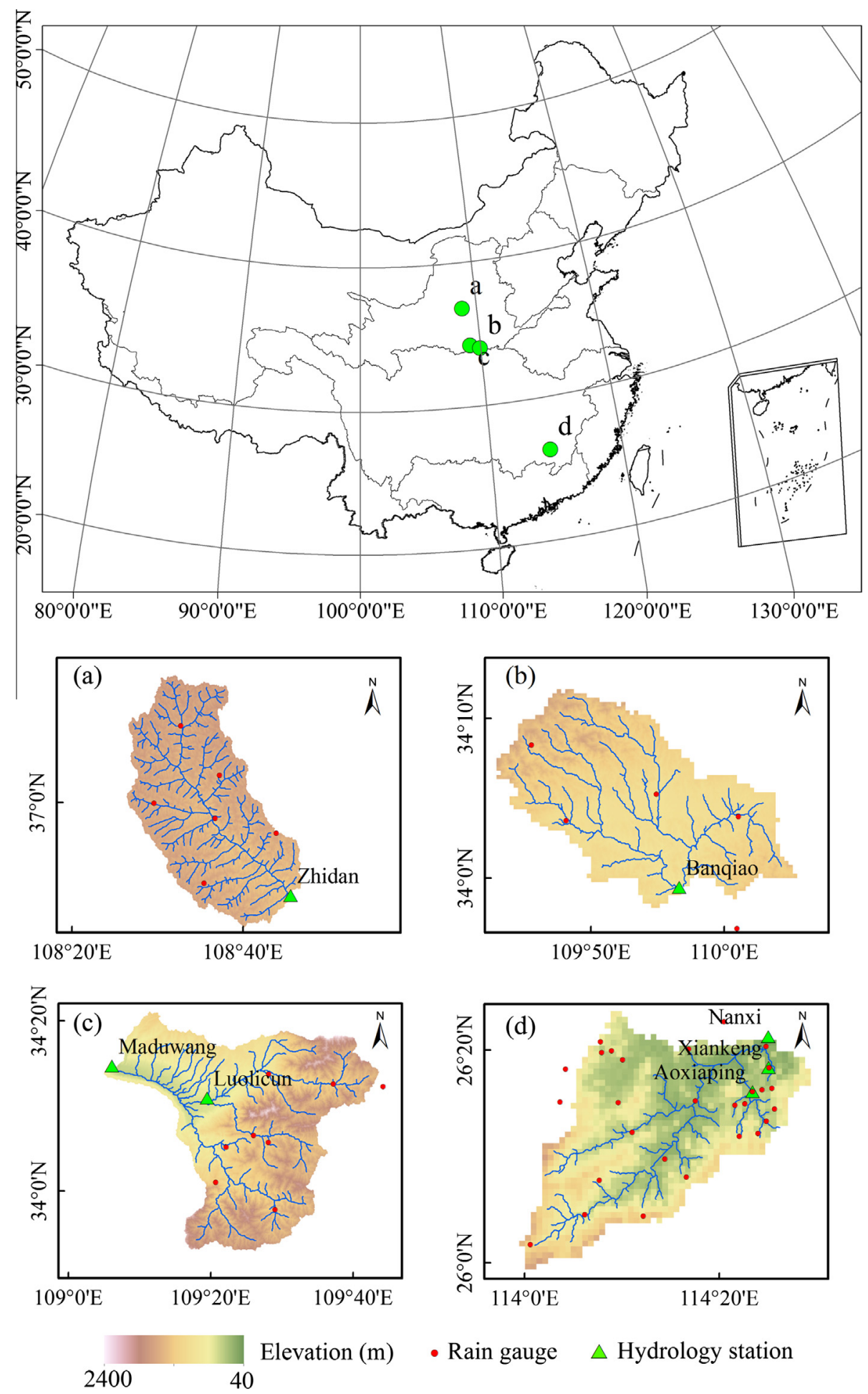

- Rain gauge $\triangle$ Hydrology station

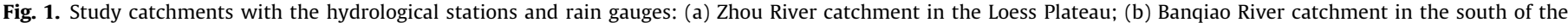
Qinling Mountains; (c) Ba River catchment in the north of the Qinling Mountains; (d) Suichuan River catchment in East China.

equation. Subsurface flow along the hillslope occurs when the soil water content surpasses the field capacity. Groundwater aquifers are discretized (corresponding to the grids) and treated as several individual storage compartments. The exchange water between the groundwater and river channel is expected to be a steady flow and is estimated by Darcy's law (Yang et al., 2002).

Most model parameters are defined according to their physical meaning based on either actual in situ measurements or regional/global databases. Only a few parameters must be calibrated, such as the hydraulic conductivity of groundwater. GBHM parameters can be categorized into vegetation, land surface, soil water, and river parameters. A detailed description of the GBHM model parameters is provided in Table 3.

\subsection{Model implementation}

In this study, the grid resolution of the GBHM model was set to $1 \mathrm{~km}$ for the Zhou River, Ba River and Suichuan River catchments 
Table 1

Basic characteristics of the study catchments.

\begin{tabular}{|c|c|c|c|c|c|}
\hline Catchment name & Drainage area $\left(\mathrm{km}^{2}\right)$ & Elevation range $(\mathrm{m})$ & Mean annual rainfall $(\mathrm{mm})$ & Mean annual runoff (mm) & Runoff coefficient \\
\hline Zhou River catchment & 774 & $1222-1808$ & 414 & 17.5 & 0.042 \\
\hline Banqiao River catchment & 493 & $774-1692$ & 670 & 111 & 0.17 \\
\hline Ba River catchment & 1601 & $427-2413$ & 735 & 238 & 0.32 \\
\hline Suichuan River catchment & 910 & $129-1597$ & 1637 & 899 & 0.55 \\
\hline
\end{tabular}

Table 2

Availability of discharge data.

\begin{tabular}{llll}
\hline Catchment name & Hydrology station & Drainage area $\left(\mathrm{km}^{2}\right)$ & Data period \\
\hline Zhou River & Zhidan & 774 & $2000-2010$ \\
Banqiao River & Banqiao & 493 & $2000-2010$ \\
Ba River & Luolicun & 840 & $2000-2010$ \\
& Maduwang & 1601 & $2000-2010$ \\
Suichuan River & Xiankeng & 18.1 & $1976-2004$ \\
& Aoxiaoping & 105 & $1976-2004$ \\
& Nanxi & 910 & $1962-1984$ \\
\hline
\end{tabular}

Note: Daily discharge data was available in the whole period. The event-based discharge data was available only in flood seasons, and the temporal resolution varied from $6 \mathrm{~h}$ to $1 \mathrm{~h}$ when discharge increased.

Table 3

Main parameters used in GBHM.

\begin{tabular}{|c|c|c|}
\hline Category & Parameters & Estimating method \\
\hline $\begin{array}{l}\text { Land surface } \\
\text { and } \\
\text { vegetation } \\
\text { parameters }\end{array}$ & $\begin{array}{l}\text { Surface retention capacity } \\
\text { Surface Manning } \\
\text { roughness coefficient } \\
\text { Soil anisotropy ratio }\end{array}$ & $\begin{array}{l}\text { Estimated from MODIS NDVI } \\
\text { Refer to "Water requirement } \\
\text { of crop guidelines" published } \\
\text { by Food and Agriculture } \\
\text { Organization of the United } \\
\text { Nations } \\
\text { Estimated from land-use type } \\
\text { Estimated from land-use type } \\
\text { Estimated from land-use type }\end{array}$ \\
\hline $\begin{array}{l}\text { Soil water } \\
\text { parameter }\end{array}$ & $\begin{array}{l}\text { Saturated volumetric } \\
\text { moisture content } \\
\text { Residual volumetric } \\
\text { moisture content } \\
\text { Saturated hydraulic } \\
\text { conductivity } \\
\text { Parameter for soil water } \\
\text { retention curve and } \\
\text { hydraulic conductivity in } \\
\text { van Genuchten's (1980) } \\
\text { equation }\end{array}$ & $\begin{array}{l}\text { Obtained from China Dataset } \\
\text { of Soil Properties for Land } \\
\text { Surface Modeling }\end{array}$ \\
\hline $\begin{array}{l}\text { Channel } \\
\text { parameters }\end{array}$ & $\begin{array}{l}\text { River geometry } \\
\text { River Manning roughness } \\
\text { coefficient }\end{array}$ & $\begin{array}{l}\text { Estimated from the field } \\
\text { survey on the typical river } \\
\text { segments of different orders } \\
\text { Refer to relevant manual or } \\
\text { from field survey }\end{array}$ \\
\hline Others & $\begin{array}{l}\text { Hydraulic conductivity of } \\
\text { groundwater } \\
\text { Groundwater storage } \\
\text { coefficient }\end{array}$ & $\begin{array}{l}\text { From measurements or } \\
\text { calibration } \\
\text { From measurements or } \\
\text { calibration }\end{array}$ \\
\hline
\end{tabular}

a We use the same river geometry for the streams in the same order.

and $500 \mathrm{~m}$ for the Banqiao River catchment, as suggested by Yang et al. (2001, 2015). The number of sub-catchments in the Zhou River, Banqiao River, Ba River and Suichuan River were 88, 101, 153 and 59, with minimum sub-catchment areas of $1,1,0.25$ and $1 \mathrm{~km}^{2}$ and maximum sub-catchment areas of 78, 45, 25.25 and $30 \mathrm{~km}^{2}$, respectively. The GBHM simulates the hydrological processes with a one-hour time step. The original rainfall data were first downscaled to hourly data. The event-based rainfall data in the flood season were uniformly distributed throughout the rainfall duration. Regarding the daily rainfall data in the nonflood season, we first determined the duration of the rainfall in a day according to the daily rainfall amounts (the more rain, the longer the duration, up to historical statistics) and randomly determined the start time of the rainfall. Then, the daily rainfall amounts were downscaled into hourly rainfall by a normal distribution. This method may introduce uncertainty in the runoff simulation, but continuous hydrological simulation during the nonflood season was used to update the catchment's hydrological status, such as soil moisture. After this temporal downscaling, the hourly rainfall was then interpolated to grids by using an angular distance weighting method (New et al., 2000). This method selects the nearest rainfall stations within a distance of $x_{0}$ (up to 8 stations were used in this study) and calculates the distance weighting for rain station $k$ as follows:

$w_{k}=\left(e^{-x / x_{0}}\right)^{m}$,

where $x$ is the distance from the center of a grid to the station; $x_{0}$ is the attenuation distance, which was set to $40 \mathrm{~km}$ in this study; and $m$ is an adjustable parameter ( $m=4$ in this study). The distance weighting is modified according to the relative direction among stations. The correction coefficient $a_{k}$ is given as

$a_{k}=\frac{\sum_{l=1}^{n} w_{l}[1-\cos \theta(k, l)]}{\sum_{l=1}^{8} w_{l}}, \quad l \neq k$,

where $\theta(k, l)$ is the angle between stations $k$ and $l, w_{l}$ is the distance weighting of station $l$, and $n$ is the number of rain stations. The angular distance weighting is modified as follows:

$W_{k}=w_{k}\left(1+a_{k}\right)$.

Therefore, the interpolated precipitation in a grid is calculated by using the weighted average as follows:

$P_{\text {int }}=\frac{\sum_{l=1}^{n} W_{l} P_{l, o b s}}{\sum_{l=1}^{8} W_{l}}$,

where $P_{\text {int }}$ is the interpolated precipitation of the target grid and $P_{l, o b s}$ is the observed precipitation at station $l$.

\subsection{Model validation}

The GBHM was calibrated during the period of 2000-2004 and validated in the period of 2005-2010 for the Zhou River, Banqiao River and Ba River catchments. For the Suichuan River catchment, the GBHM was calibrated during the period of 1974-1978 and validated from 1979 to 1983.

Only the daily discharge was available throughout the entire period, so we first averaged the hourly simulated discharge values to a daily mean value to calculate the statistical indices. The Nash and Sutcliffe coefficient (NSE) and the correlation coefficient $\left(R^{2}\right)$ were adopted to evaluate the model performance on the daily scale, which are defined as

$N S E=1-\frac{\sum_{t=1}^{T}\left(Q_{o}^{t}-Q_{s i m}^{t}\right)^{2}}{\sum_{t=1}^{T}\left(Q_{o}^{t}-\overline{Q_{0}}\right)^{2}}$ 
$R^{2}=\frac{\left(\sum_{t=1}^{T}\left(Q_{\text {sim }}^{t}-\overline{Q_{s i m}}\right)\left(Q_{o}^{t}-\overline{Q_{o}}\right)\right)^{2}}{\sum_{t=1}^{T}\left(Q_{\text {sim }}^{t}-\overline{Q_{\text {sim }}}\right)^{2} \sum_{t=1}^{T}\left(Q_{o}^{t}-\overline{Q_{o}}\right)^{2}}$,

where $Q_{0}^{t}$ and $Q_{\text {sim }}^{t}$ denote the observed and simulated discharge and $\overline{Q_{\text {sim }}}$ and $\overline{Q_{0}}$ denote the average values of the simulated and observed discharges, respectively, during the simulation period $T$.

The six flood events with the largest peak discharges for the four hydrological stations at the outlets of the study catchments were selected according to the continuous simulation results from the GBHM at a one-hour time step in the four study catchments to evaluate the model performance for event flood simulation.

\section{Method to determine the rainfall threshold for flood warning}

Computing the rainfall threshold for flood warnings mainly consists of two steps: (1) determining the discharge threshold for flood warnings based on simulations of historical floods from 1951 to 2002 in the Suichuan catchment and from 2000 to 2010 in the other three catchments, and (2) determining the rainfall threshold that induces the flood discharge threshold.

\section{(1) Determining the discharge threshold for flood warnings}

The flood threshold has been conventionally considered as the bank-full flow (Ntelekos et al., 2006; Schmidt et al., 2007; Gourley et al., 2012), which is often characterized by a two-year return period. Observed river discharge data were lacking for most of the small catchments (the interior sub-catchments) in this study, so we first determined the magnitude of the flooding threshold at the outlet of each study catchment based on the observed discharge according to the local flood situation as obtained from field surveys. We could determine the return period (or frequency) of the flooding threshold through a frequency analysis based on historical flood data. Then, we used the same return period (or frequency) as the return period threshold to determine the flooding threshold based on the simulated discharge for all the subcatchments within a study catchment.

A 98-m water level was set as the water level threshold for Nanxi station at the outlet of the Suichuan River catchment (see Fig. 1) according to field surveys. Then, we determined the flooding threshold to be $740 \mathrm{~m}^{3} / \mathrm{s}$ based on the stage-discharge relationship at Nanxi station. We estimated the frequency of this flooding threshold to be 0.23 , which is roughly equal to the five-year return period, based on historical floods. Then, we determined the flooding threshold to be $802 \mathrm{~m}^{3} / \mathrm{s}$ for the outlet of the Nanxi catchment according to the frequency analysis of simulated flood discharge. The flooding thresholds that were calculated with the simulated discharges for the four study catchments are shown in Table 7. These flooding thresholds were then used to determine the rainfall thresholds. Flood frequency analysis requires long-term data, so a flood with a two-year return period was chosen as the flooding threshold for warnings because of the limited available discharge data period (see Table 2) and the local flood conditions in the Zhou River catchment, Banqiao River catchment and Ba River catchment.

As stated in Reed et al. (2007), the simulated discharge-based flow threshold can be effectively used as an indicator of relative flood severity as long as the hydrologic model can effectively ranking events, even if the forecast peak flows are biased relative to the observed data. This skill depends on the consistency of the precipitation inputs and the model. The precipitation inputs in this study originated from rain gauges with the same instruments, and the GBHM model was well calibrated and validated. Therefore, we deem that the consistency of the precipitation inputs and the model accuracy are satisfied.
Because most of the sub-catchments in the study areas were ungauged (lack of river level or discharge observations), the GBHM was employed to simulate historical floods by using observed meteorological data as the inputs. We used frequency analysis based on these simulated floods to determine the flooding thresholds with the same return period thresholds for each subcatchment within a study catchment.

(2) Determining the rainfall threshold for flood discharge warnings

After determining the flooding threshold, we can further derive the rainfall threshold with time spans from 1 to $12 \mathrm{~h}$ based on GBHM simulations of the hourly discharge and soil moisture.

First, we selected all the flood events from the entire period of available data (as indicated in Table 2) with a peak discharge that was greater than $1 / 5$ of the required threshold value for flood warnings. In total, 216, 128, 86 and 90 flood events were selected for the Suichuan catchment, Maduwang catchment, Banqiao catchment and Zhidan catchment, respectively. We found the maximum rainfall values that accumulated over time spans from $1 \mathrm{~h}$ to $12 \mathrm{~h}$ by looking back from each peak discharge up to one day before, and the soil moisture before each rainfall event was selected as the antecedent soil moisture content of each flood. Typically, the soil type (or the soil porosity) is not spatially uniform in a sub-catchment, so we used the soil saturation $(S)$ instead of the volumetric soil water content for simplicity, which is defined as

$S=\frac{\theta}{\theta_{s}}$,

where $\theta$ is the soil moisture and $\theta_{S}$ is the saturated soil moisture.

The next step was to determine whether a given rainfall was greater than or less than the rainfall threshold by a linear (for simplicity) binary classification of value pairs of the maximum cumulative rainfall and degree of soil saturation, as shown in Fig. 2. We plotted the accumulated rainfall against the soil saturation. Then, the pairs of maximum cumulative rainfall and degree of soil saturation that corresponded to simulated peak discharges that were equal to or greater than the flooding threshold (computed with the simulated discharge) were grouped into pattern-1 (marked as red $^{1}$ squares in Fig. 2), while the pairs that corresponded to peak discharges that were smaller than the flooding threshold were grouped into pattern-2 (marked as blue dots). Then, the procedure became a binary classification problem, and we could establish whether a given rainfall was greater than or less than the rainfall threshold value. The least mean squares algorithm, which is also called the Widrow-Hoff algorithm (Widrow and Hoff, 1960), was applied to determine the discriminant function to minimize the classification errors.

The linear discriminant function $d(\mathbf{x})$ is defined as

$d(\mathbf{x})=w_{1} p+w_{2} s+w_{3}=\mathbf{w x}\left\{\begin{array}{ll}\leqslant 0, & \text { pattern-1 } \\ >0, & \text { pattern- } 2\end{array}\right.$,

where $\mathbf{x}=(p, s, 1)$ represents a group of accumulated precipitation and initial soil saturation values and $\mathbf{w}=\left(w_{1}, w_{2}, w_{3}\right)$ is the pending coefficient. Then, $d(\mathbf{x})<\mathbf{0}$ indicates a situation when a flood exceeds the flooding threshold. If we multiply $\mathbf{x}$ from pattern-1 by -1 , we obtain $\tilde{\mathbf{x}}=(-p,-s,-1)$, and the discriminant function becomes

$d(\tilde{\mathbf{x}})=\mathbf{w} \tilde{\mathbf{x}} \begin{cases}>0, & \text { correct classification } \\ \leqslant 0, & \text { false classification }\end{cases}$

\footnotetext{
${ }^{1}$ For interpretation of color in Figs. 2 and 3, the reader is referred to the web version of this article.
} 


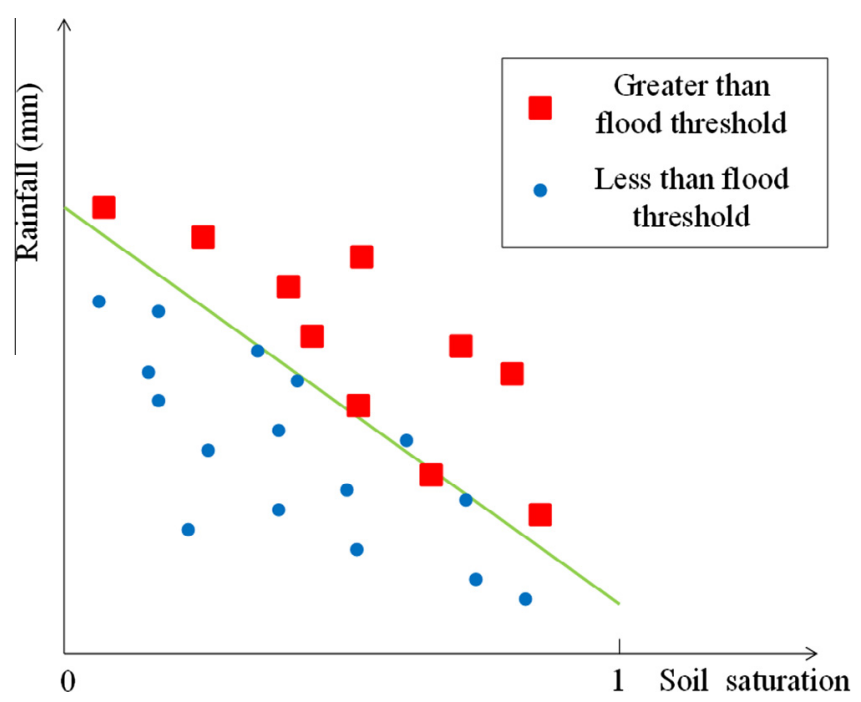

Fig. 2. Schematic diagram of binary classification.

Table 4

Contingency table for performance estimation.

\begin{tabular}{lll}
\hline Events occurrence & Events forecasted \\
\cline { 2 - 3 } & Yes & No \\
\hline Yes & $H$ (hits) & $M$ (misses) \\
No & $F A$ (false alarms) & Correct negatives \\
\hline
\end{tabular}

Eq. (9) can be further expressed as a matrix equation:

$\mathbf{X w}=\mathbf{b}$,

where $\mathbf{X}=\left(\tilde{\mathbf{x}}_{1}, \tilde{\mathbf{x}}_{\mathbf{2}}, \tilde{\mathbf{x}}_{\mathbf{3}}, \ldots \tilde{\mathbf{x}}_{\mathbf{N}}\right)$ and $\mathbf{b}$ is the residual vector. Given the value of $\mathbf{b}$, the calculation of $\mathbf{w}$ is equivalent to minimizing the variance function $J(\mathbf{w})$ by using the optimization algorithm:

$J(\mathbf{w})=(\mathbf{X w}-\mathbf{b})^{\prime}(\mathbf{X w}-\mathbf{b})$.

Obviously, the solution of $\mathbf{w}$ depends on the choice of $\mathbf{b}$. However, $\mathbf{w}$ values that are calculated from different $\mathbf{b}$ are similar. Studies have suggested that $\mathbf{b}=[1,1, \ldots, 1]$ has suitable properties, so $\mathbf{b}=[1,1, \ldots, 1]$ was applied in this study.

In real-time operational practices, the soil saturation can be updated continuously (every one hour) through the computation of GBHM by using the observed rainfall as the input. With the classifier, the rainfall thresholds under different soil moisture conditions can be directly taken from the graphs. A decision regarding whether to issue a warning can be made by comparing the rainfall threshold value that was obtained from the classifier with the observed now-casted or forecasted rainfall value.

A contingency table has been frequently used in similar studies to evaluate the performance of forecast systems. As shown in Table $4, H$ (hits) denotes the number of positive forecasts that correspond to the occurrence of an event, $M$ (misses) denotes the number of events that occurred but were missed by the forecast, and $F A$ (false alarms) denotes false alerts that were forecasted but did not actually occur (Schaefer, 1990). According to this contingency table, the three statistics of the probability of detection (POD), the false alarm rate (FAR) and the critical success index (CSI) are used to assess the performance of the method:

$$
\begin{aligned}
& \mathrm{POD}=\frac{H}{H+M} \\
& \mathrm{FAR}=\frac{F A}{H+F A} \\
& \mathrm{CSI}=\frac{H}{H+M+F A}=\frac{1}{\mathrm{POD}^{-1}+(1-\mathrm{FAR})^{-1}-1}
\end{aligned}
$$

The POD ranges from 0 to 1 , and POD $=1$ for a perfect hit. The FAR also ranges from 0 to 1 , and FAR $=0$ indicates a zero false positive rate. The CSI ranges from 0 to 1 . A higher POD value and a lower FAR value correspond to a higher CSI value.

\section{Results and discussion}

\subsection{Performance of GBHM in different climate regions}

Table 5 lists the NSE and $R^{2}$ values for the simulated daily discharges in the four study catchments. We found NSE values of approximately 0.8 and $R^{2}$ values of approximately 0.9 for most of the catchments during the calibration period, with the exception of the Zhidan catchment (NSE $=0.49, R^{2}=0.72$ ). Fig. 3 shows the hourly simulations of the top 6 flood events during the rainy season, in which the red dots represent the observed discharge, the blue line represents the simulated discharge, and the upper bars represent the mean catchment rainfall. Table 6a summarizes the peak discharge, relative error of the flood peak, and time difference of the simulated peak compared to the observed flood peak. The results in Table 6a show that the model could simulate most flood events appropriately, with the relative errors of most flood peaks smaller than $20 \%$ and the peak time differences within $2 \mathrm{~h}$. Table $6 \mathrm{~b}$ shows the results in three interior sub-catchments without calibration. The relative error of the flood peaks increased, but the timing error of the flood peaks was around the same magnitude as that for the calibrated sites. A bigger error was found in smaller catchments.

At the same time, the performance of GBHM in the semi-arid catchment (Zhidan catchment) was worse than that in the other catchments. This result may be explained by the low temporal resolution of the rainfall data. The temporal scale is especially important for hydrological simulations in arid areas because the excess infiltration runoff predominates, which can be demonstrated from the sharp flood hydrographs in Fig. 3(a) (Zhidan). Li et al. (2015) tested several hydrological models in the Zhidan catchment by using the same rainfall data as inputs, but all the simulation results were unsatisfactory, and the authors reported that poor vegetation development and soil hardening might also explain the poor model performance. Moreover, Duan (2010) and Wang (2011) reported

\begin{tabular}{|c|c|c|c|c|c|}
\hline \multirow[t]{2}{*}{ Catchment name } & \multirow[t]{2}{*}{ Hydrological station } & \multicolumn{2}{|c|}{ Calibration period } & \multicolumn{2}{|c|}{ Validation period } \\
\hline & & NSE & $R^{2}$ & NSE & $R^{2}$ \\
\hline (a) Zhou River catchment & Zhidan & 0.49 & 0.72 & 0.12 & 0.23 \\
\hline (b) Banqiao River catchment & Banqiao & 0.82 & 0.9 & 0.68 & 0.88 \\
\hline (c) Ba River catchment & Maduwang & 0.82 & 0.91 & 0.77 & 0.89 \\
\hline (d) Suichuan River catchment & Nanxi & 0.81 & 0.92 & 0.88 & 0.95 \\
\hline
\end{tabular}

Table 5

GBHM performance for daily discharge simulation during the calibration and validation periods. 

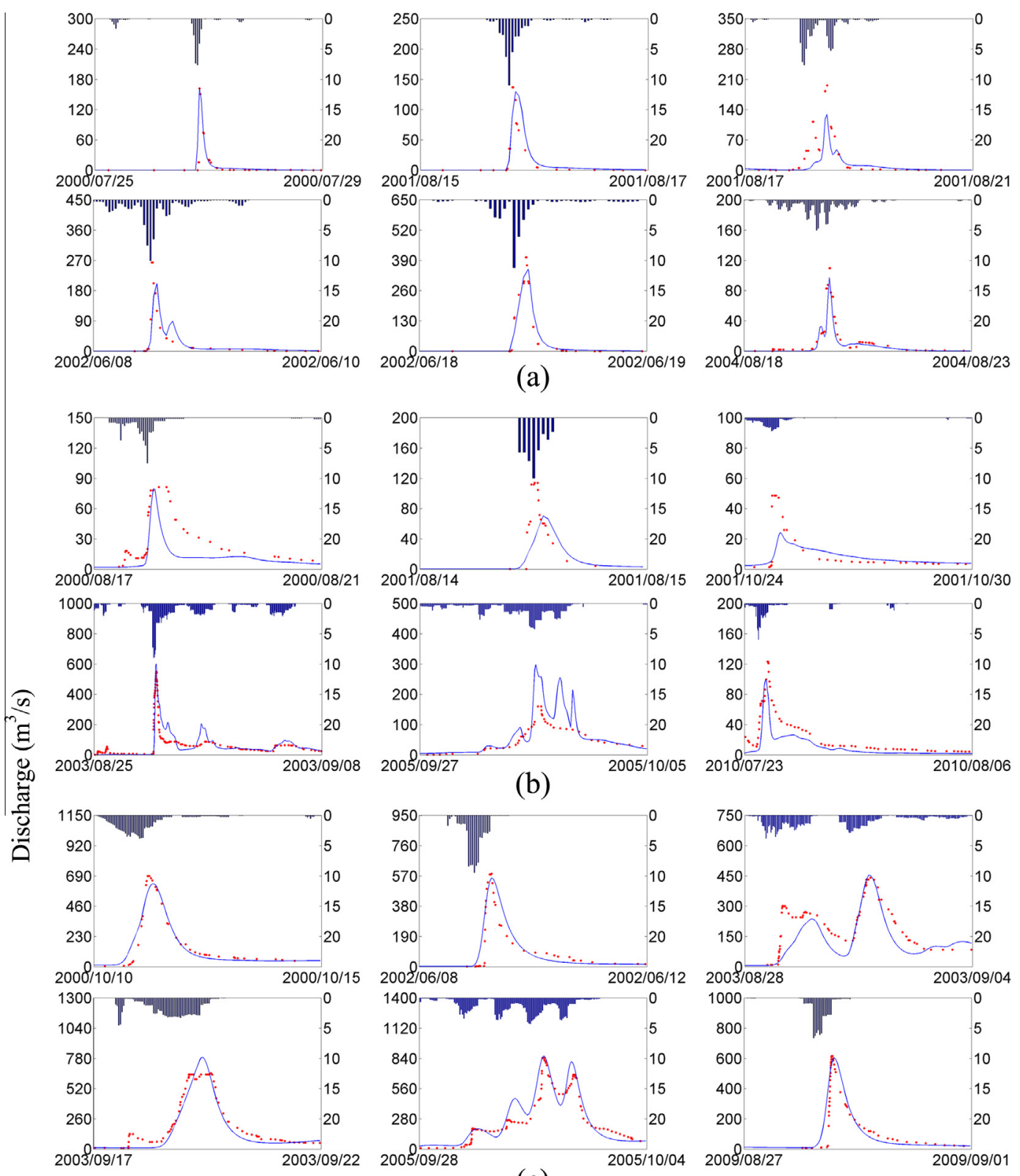

(b)
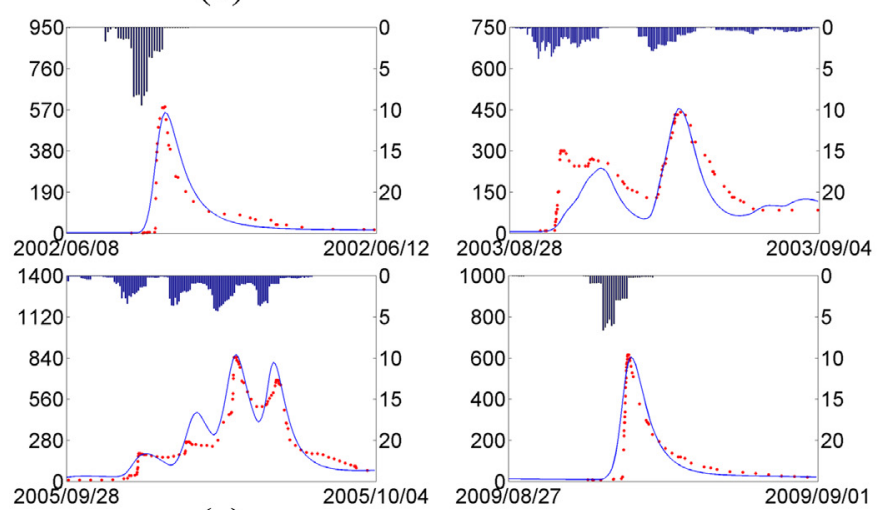

(c)
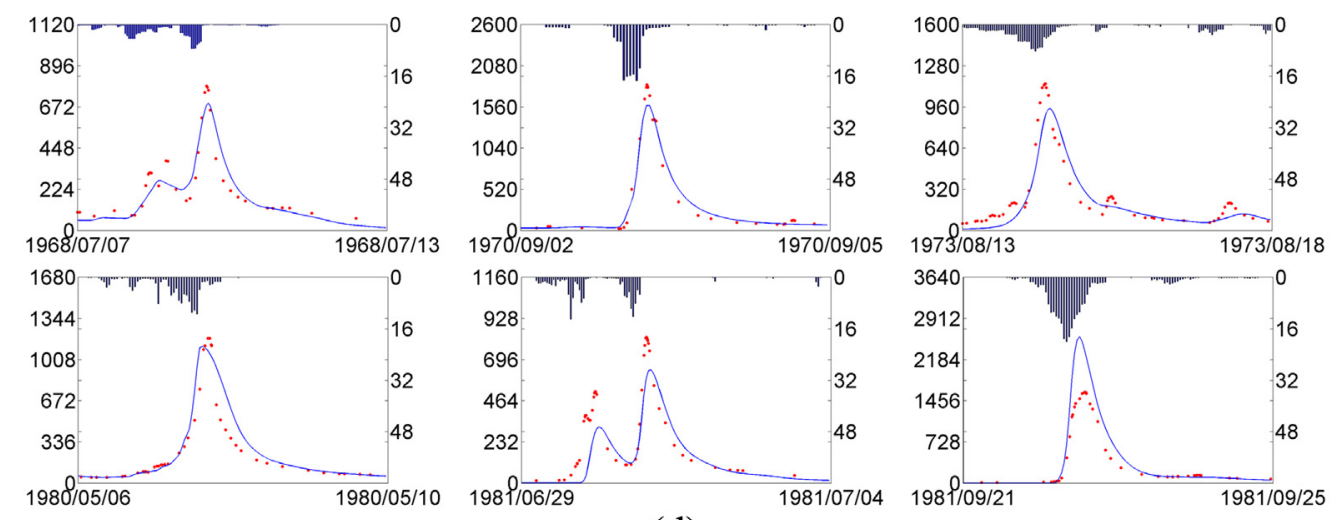

(d)

Fig. 3. Hourly simulation results of six top flood process at four gauged stations: (a) Zhidan; (b) Banqiao; (c) Maduwang; (d) Nanxi. 
Table 6a

Validation of GBHM in the gauged catchments.

\begin{tabular}{|c|c|c|c|c|c|c|c|c|c|}
\hline Station & Year-month-day & $Q\left(\mathrm{~m}^{3} / \mathrm{s}\right)$ & Error (\%) & Time $(\mathrm{h})$ & Station & Year-month-day & $Q\left(\mathrm{~m}^{3} / \mathrm{s}\right)$ & Error (\%) & Time $(\mathrm{h})$ \\
\hline \multirow[t]{6}{*}{ Zhidan } & $2000-07-27$ & 162 & 1 & 0 & \multirow[t]{6}{*}{ Banqiao } & $2000-08-18$ & 81.2 & -2 & -3 \\
\hline & $2001-08-16$ & 137 & -5 & 0.7 & & 2001-08-15 & 114 & -38 & 1.2 \\
\hline & 2001-08-18 & 196 & -34 & 0 & & $2001-10-24$ & 48.7 & -25 & 3 \\
\hline & 2002-06-08 & 264 & -24 & 1.3 & & 2003-08-29 & 550 & 9 & 0 \\
\hline & 2002-06-18 & 403 & -13 & 0.4 & & 2005-10-01 & 160 & 86 & -2 \\
\hline & 2004-08-20 & 110 & -12 & 0 & & 2010-07-02 & 123 & -19 & -3 \\
\hline \multirow[t]{6}{*}{ Madu-wang } & 2000-10-11 & 688 & -8 & 2 & \multirow[t]{6}{*}{ Nanxi } & 1968-07-09 & 785 & -12 & 1 \\
\hline & 2002-06-09 & 584 & -4 & 0 & & 1970-09-03 & 1840 & -14 & 0.9 \\
\hline & 2003-09-01 & 441 & 3 & -1 & & 1973-08-15 & 1140 & -17 & 2.3 \\
\hline & $2003-09-20$ & 652 & 21 & -5 & & 1980-05-08 & 1180 & -5 & -2.2 \\
\hline & 2005-10-01 & 844 & 2 & 0 & & 1981-07-01 & 821 & -22 & 1.8 \\
\hline & 2009-08-29 & 616 & -2 & 1 & & 1981-09-22 & 1610 & 61 & -1.9 \\
\hline
\end{tabular}

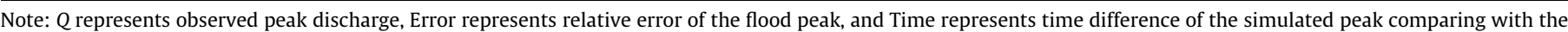
observed flood.

Table 6b

Validation of GBHM in the interior sub-catchments without calibration.

\begin{tabular}{lllrr}
\hline Station & Year-month-day & $Q\left(\mathrm{~m}^{3} / \mathrm{s}\right)$ & Error $(\%)$ & Time $(\mathrm{h})$ \\
\hline \multirow{2}{*}{ Luolicun } & $2000-10-11$ & 341 & 6 & -2.0 \\
& $2002-6-9$ & 268 & 45 & 2.5 \\
& $2004-9-30$ & 483 & -48 & -0.3 \\
& $2005-10-1$ & 491 & 2 & -1.8 \\
& $2009-8-29$ & 312 & 46 & -0.5 \\
Xiankeng & $2009-9-20$ & 441 & -65 & 0.0 \\
& $1979-6-29$ & 50.6 & -66 & 0.6 \\
& $1981-9-22$ & 38.9 & 84 & -0.4 \\
& $1985-7-3$ & 36.6 & 12 & 0.0 \\
& $1991-9-8$ & 37.2 & 39 & -0.1 \\
& $1997-7-22$ & 43.4 & -62 & 1.1 \\
& $1997-8-9$ & 46.9 & -51 & 0.7 \\
Aoxiaping & $1976-5-20$ & 321 & -86 & 0.4 \\
& $1976-8-11$ & 279 & -55 & 1.1 \\
& $1984-4-3$ & 270 & -85 & -1.0 \\
& $1991-6-19$ & 259 & 5 & 0.0 \\
& $1991-9-8$ & 234 & 33 & -0.1 \\
& $2000-6-20$ & 264 & 22 & -0.2 \\
\hline
\end{tabular}

that 615 warping dams with a total storage of 830 million $\mathrm{m}^{3}$ were built in Zhidan County $\left(3781 \mathrm{~km}^{2}\right)$, where the Zhidan catchment is located. This observation might explain the poor model performance in the Zhidan catchment because the GBHM did not consider landscape changes.

In addition, decay in the model performance (in terms of NSE and $R^{2}$ ) from the calibration period to the validation period is particularly evident for the Zhidan catchment. The Mann-Kendall trend test (Mann, 1945; Kendall, 1975) was used to detect the trends of rainfall from 2001 to 2010 . The results showed a decreasing trend with a significance level of 0.05 for the annual rainfall and the 24-h maximum rainfall. The changing rainfall climatology, especially the decrease in the 24-h maximum rainfall, may have induced this decay in the model performance. The reason for this result might be related to the GBHM calculating the excess infiltration at 1-h time steps. We used event-based rainfall data rather than hourly data; the rainstorms may have exhibited high temporal variability, but we used the average rainfall for each event as hourly inputs into GBHM without changing other parameters. Additionally, the performance of the GBHM in the Ba River catchment under similar climate conditions was better than that in the Banqiao River catchment, which indicates that other basin characteristics, such as rain gauge networks, can also influence the model's performance. In terms of the number of stations and spatial distribution over the basin, the rain gauge network in the Ba River catchment was better than that in the Banqiao River catchment. This observation also explains the better performance for the Ba River catchment comparing to that for the Banqiao River catchment. In general, the model's performance was better in humid catchments than in arid catchments. Because excess infiltration runoff predominates in arid catchments, hightemporal-resolution rainfall data and better simulations of the soil water dynamics are required to improve flood simulations.

\subsection{Flash flood warnings based on rainfall thresholds}

We estimated the time of the flood peak in response to the storm peak in each sub-catchment based on the simulated hourly discharge and the mean catchment rainfall. Fig. 4 illustrates the response time of each sub-catchment against the catchment drainage area. The response time in this study is defined as the time between the maximum hourly mean catchment rainfall and the peak of the simulated hourly discharge from the GBHM, which is averaged over all events during the entire simulation period. Because the time step of the GBHM was one hour, the flood response times in several very small sub-catchments were expected to be overestimated. Fig. 4 shows that the response time increased with the catchment area; a response time of $3 \mathrm{~h}$ roughly corresponded to catchment areas of $30,196,88$ and $135 \mathrm{~km}^{2}$ for the Zhou River, Banqiao River, Ba River and Suichuan River catchments, respectively. The catchments with drainage areas from tens to hundreds of square kilometers in the mountainous regions are usually in China's rural areas. Thus, flood warnings that are based on the rainfall threshold are especially useful for small rural catchments according to the actual situations in China's rural areas, where rain gauges are the only instruments that can be used for flash flood forecasting. Therefore, we must evaluate if a flood warning method based on rainfall thresholds provides satisfactory outcomes over the study area. Fig. 5 provides the binary classification results for the four study catchments (with simulation results from 1951 to 2002 for the Suichuan catchment and from 2000 to 2010 for the other three catchments). The accumulative rainfalls for 1$\mathrm{h}, 3-\mathrm{h}, 6-\mathrm{h}$ and $12-\mathrm{h}$ periods are shown in this figure as examples, from which we can easily estimate the value of the rainfall threshold for a certain duration and particular soil saturation. Table 7 lists the rainfall thresholds for flood warnings at the outlets of the four study catchments with time spans of $1 \mathrm{~h}, 3 \mathrm{~h}, 6 \mathrm{~h}$ and $12 \mathrm{~h}$ for soil saturation values of $0.25,0.5$ and 0.75 . In practice, we can directly refer to this table to estimate the rainfall threshold under different soil saturations through linear interpolation. The rainfall threshold increased with the duration and decreased with increasing soil saturation in all the study catchments, especially in the Suichuan River catchment.

We determined the rainfall thresholds for the ungauged subcatchments in the study areas in the same manner. Fig. 6 provides the binary classification results for three interior "ungauged" 
catchments (Luolicun, Xiankeng and Aoxiaping), and Fig. 7 shows the spatial distribution of the rainfall thresholds with a duration of $3 \mathrm{~h}$ under a soil saturation of $50 \%$ in the four catchments. The spatial distributions of the rainfall thresholds over 1-h, 6-h and 12-h time spans were similar to that for a 3-h time span. The rainfall threshold exhibited high variability among the four study catchments and within the same study catchment. The spatial variability of the rainfall threshold was closely related to the catchment's hydrological variability, which indicates that estimating the rainfall threshold on a small spatial scale is necessary to assist local flash flood warnings.

A comprehensive evaluation of the proposed method was performed through three steps: (1) assessing the accuracy of the binary classification, (2) assessing the reliability of the proposed rainfall thresholds based on the historical rainfall, and (3) assessing the performance of the proposed method by directly comparing the model-simulated floods with the observed floods. The indices for the accuracy assessment, including the POD, FAR and CSI, were then calculated for the periods during which discharge data were available (as shown in Table 2). First, the accuracy of the binary classification was evaluated by using all the available data. Here, hits $(H)$ indicate when the positions of the pairs of maximum cumulative rainfall and degree of soil saturation corresponded to positive events (the simulated runoff exceeded the runoff threshold) that lay above the discriminant line, misses $(M)$ indicate when the position of the pairs that correspond to positive events lay under the discriminant line, and false alarms $(F A)$ indicate when the position of the pairs that correspond to negative events (the simulated runoff did not exceed the runoff threshold) lay above
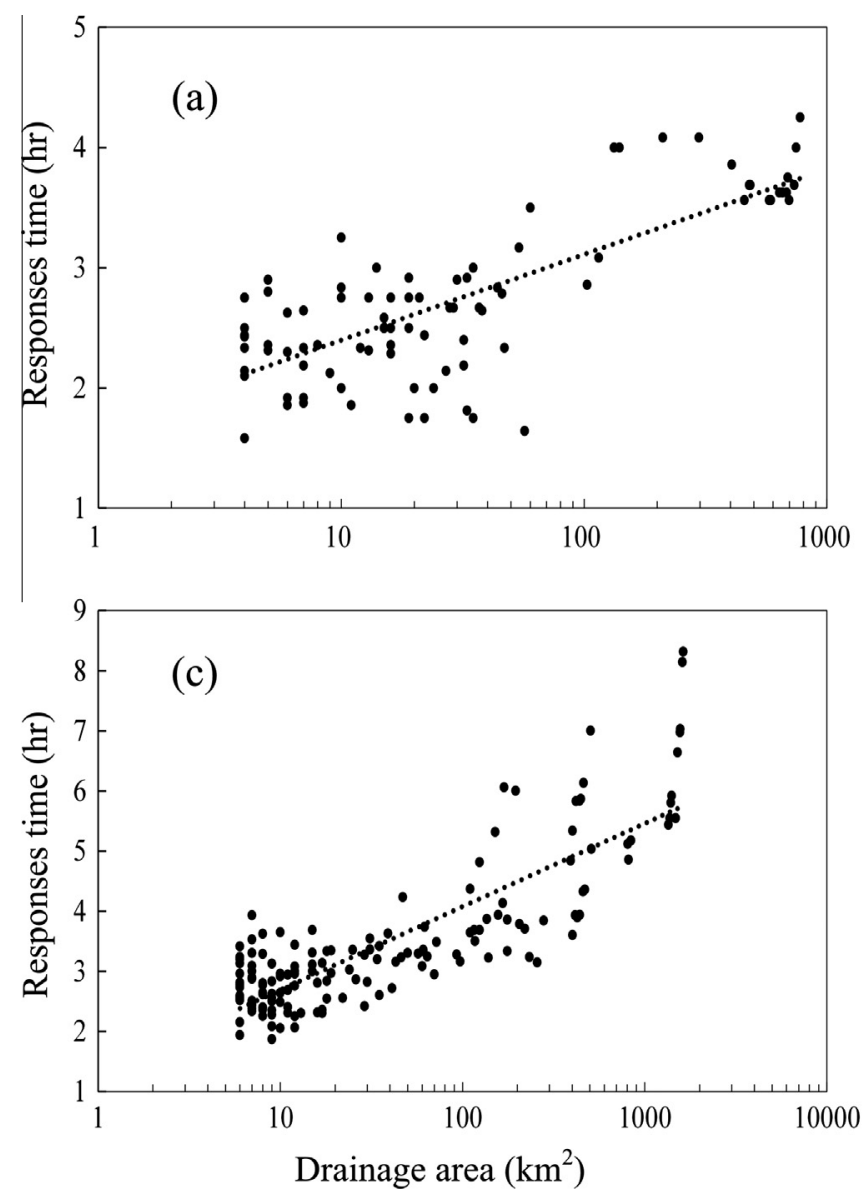

the discriminant line. We calculated the three indices after the contingency table was built, as shown in Table 8a. In total, 11, 14, 10 and 9 flood events (in terms of the simulated discharge) exceeded the flooding threshold for the Zhidan catchment, Banqiao catchment, Maduwang catchment and Suichuan catchment, respectively. The CSI values for different rainfall durations in the four study catchments ranged from 0.28 to 0.77 , the POD values ranged from 0.44 to 0.91 , and the FAR values ranged from 0.64 to 0.17 , which indicate that the accuracy of the binary classification was reasonable. Table 8 a showed that the statistical values varied among different study catchments. The accuracy of binary classification was better in the Zhou River (Zhidan catchment) located in the semi-arid region comparing with other study catchments. This implied that flash flood has better relation with the rainfall in this catchment. In the same study catchment the statistical values of different time spans were also different. The accuracy of the binary classification for the rainfall thresholds over 1 -h and 12-h periods was worse compared to the 3 -h and 6-h rainfall thresholds. The 12 $\mathrm{h}$ time span was generally longer than the concentration times of the study catchments, while 1-h rainfall time spans may not exceed the capacity of canopy interception and surface detention. These results may explain why the performance for the 1-h and 12-h rainfall thresholds was worse and implies that the 3-h and 6-h rainfall thresholds were more meaningful for flood warnings in watersheds with similar sizes to the study catchments. We focus on these 3-h and 6-h rainfall thresholds below, although we will provide all the $1-\mathrm{h}, 3-\mathrm{h}, 6-\mathrm{h}$ and $12-\mathrm{h}$ values.

Second, the reliability of the proposed rainfall threshold for flash flood warning was assessed by using the observed rainfall
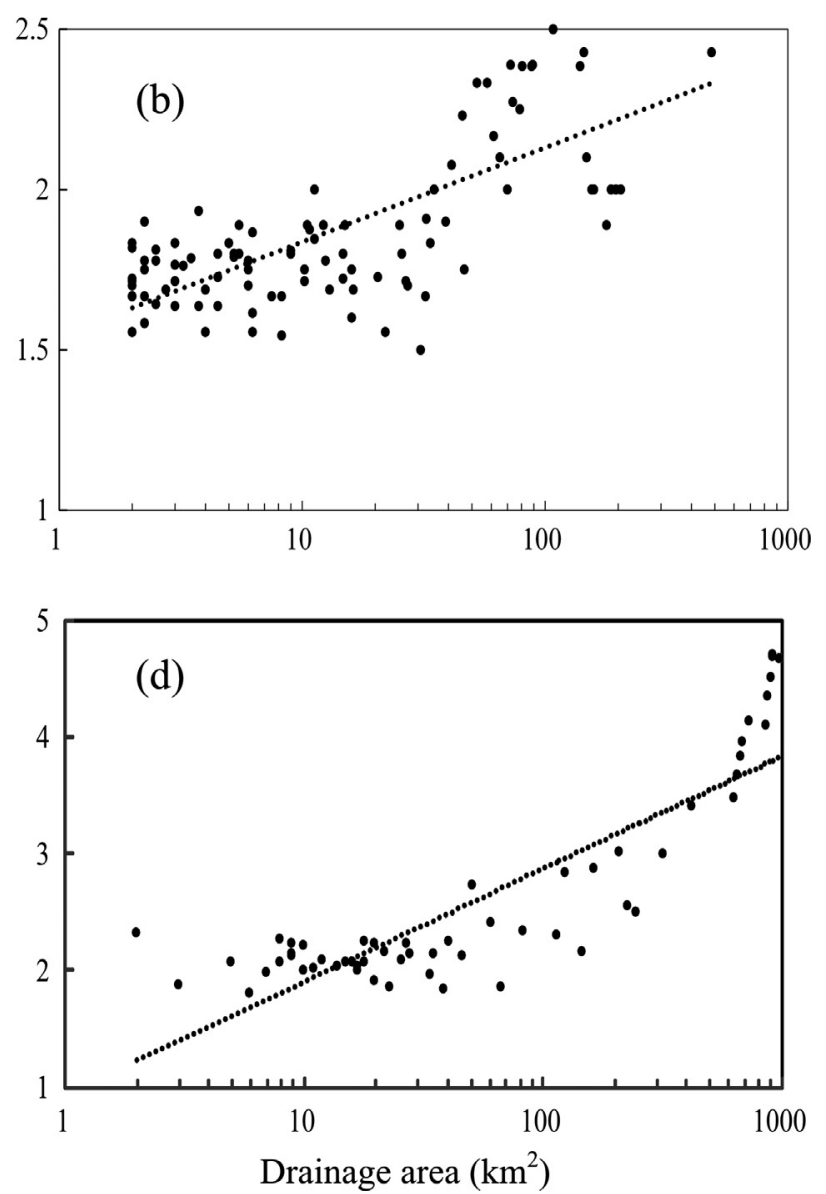

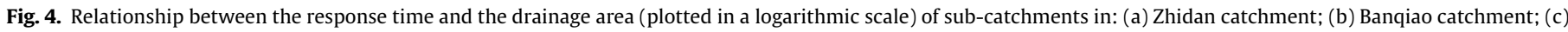
Maduwang catchment; (d) Nanxi catchment. 
- Smaller than threshold $\square$ Larger than threshold $\quad$ Discriminant function
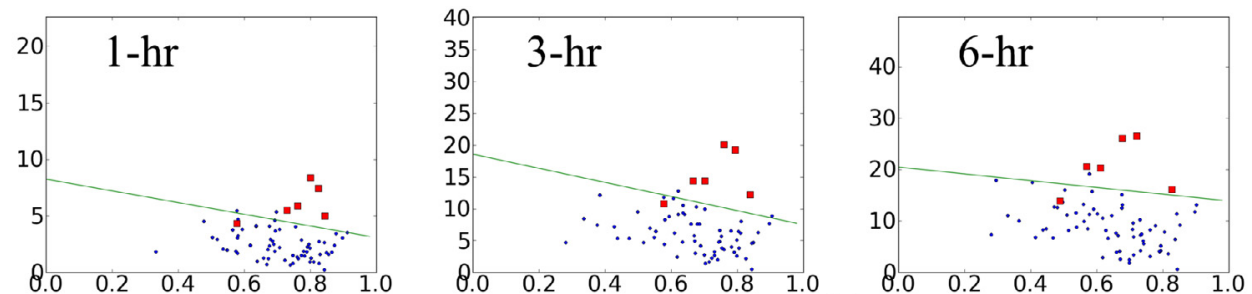

(a)
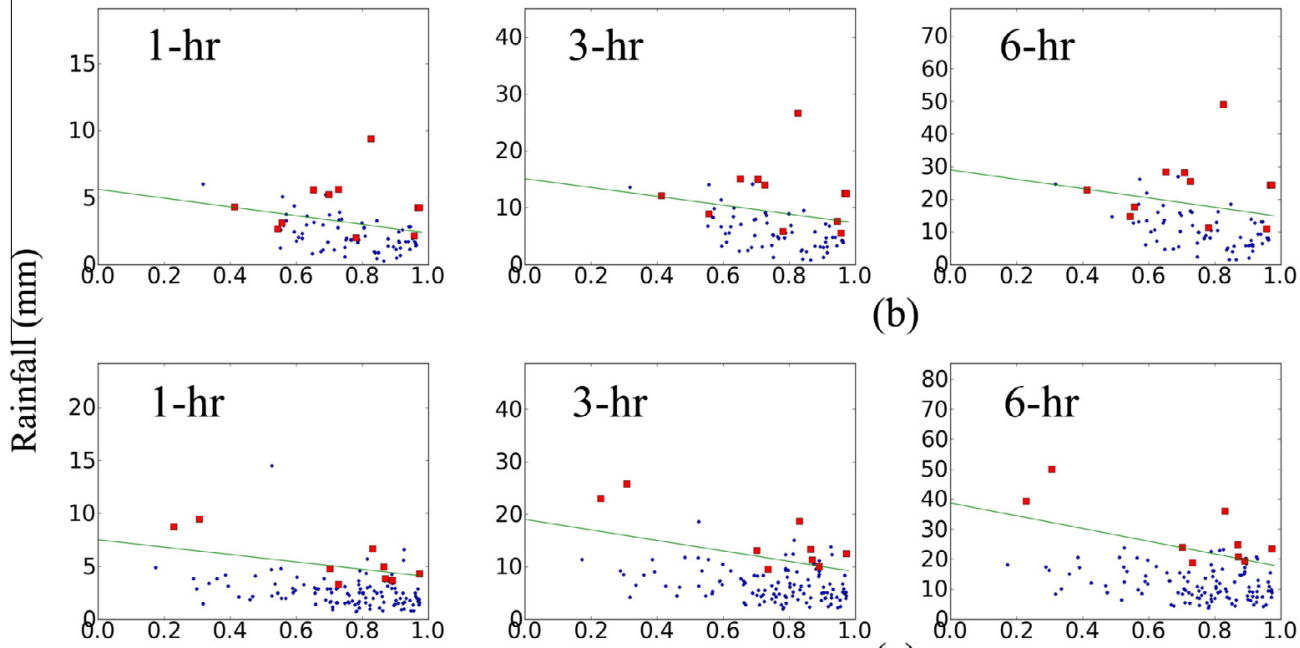

(b)
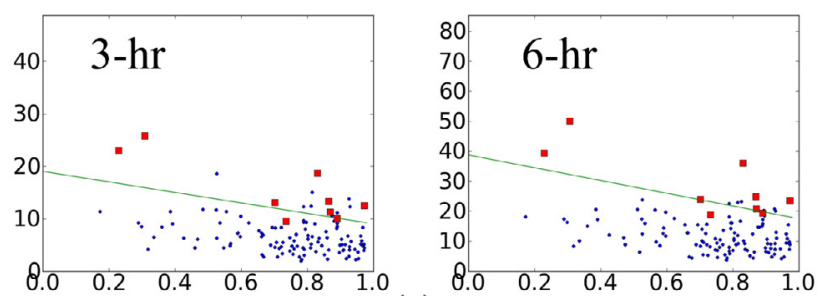

(c)
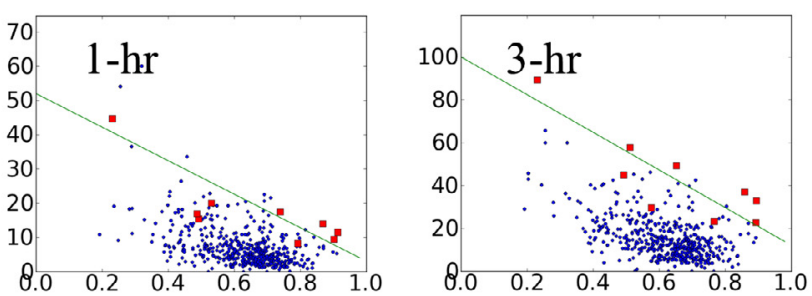
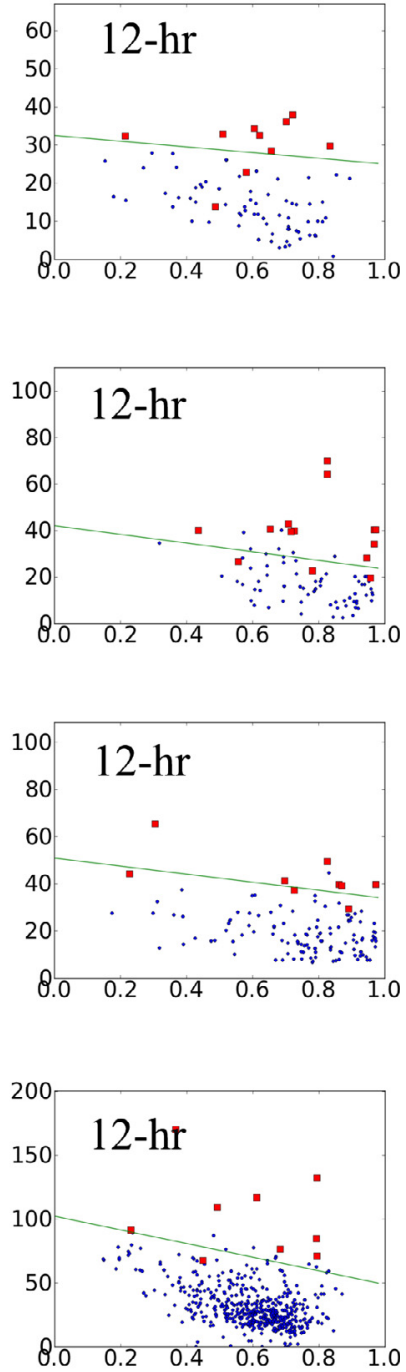

(d)

\section{Soil Saturation}

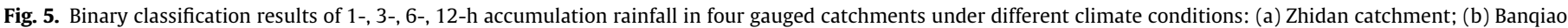
catchment; (c) Maduwang catchment; (d) Nanxi catchment.

and discharge in the entire period when event data were available, which means that the assessment was performed as a "hindcast". The rainfall threshold was calculated based on the temporal soil moisture at each hour through the entire period when observed discharge values were available. Then, the subsequently observed rainfall for each rainfall time span was compared to the rainfall threshold of the corresponding duration to decide whether a flood warning should be issued. Meanwhile, the observed discharge was compared to the flooding threshold to determine whether a flood occurred. Here, the flooding threshold was obtained with frequency analysis that was based on historically observed discharge data. For each time span, a flood event was considered to have occurred if at least one of the hourly observed discharges exceeded the flooding threshold in the next time span following the current time. Then, the accuracy indices were calculated, as shown in Table 8b. The CSI values here are slightly lower than those in Table 8a, but all are well above the benchmark skill of 0.2 that was suggested by Clark et al. (2014) for the US NWS's FFG on a national scale.
Table 7

Rainfall threshold and flood threshold for flood warning at the outlet of the study catchments (unit: $\mathrm{mm}$ ).

\begin{tabular}{|c|c|c|c|c|c|}
\hline \multirow[t]{2}{*}{ Station } & \multirow[t]{2}{*}{ Threshold flood $\left(\mathrm{m}^{3} / \mathrm{s}\right)$} & \multirow[t]{2}{*}{ Duration (h) } & \multicolumn{3}{|c|}{ Saturation } \\
\hline & & & 0.25 & 0.5 & 0.75 \\
\hline \multirow[t]{4}{*}{ Zhidan } & 83 & 1 & 6.9 & 5.7 & 4.4 \\
\hline & & 3 & 15.8 & 13.0 & 10.2 \\
\hline & & 6 & 18.8 & 17.2 & 15.5 \\
\hline & & 12 & 26.3 & 24.8 & 23.4 \\
\hline \multirow[t]{4}{*}{ Banqiao } & 76 & 1 & 4.8 & 4.0 & 3.1 \\
\hline & & 3 & 13.1 & 11.2 & 9.2 \\
\hline & & 6 & 25.4 & 21.8 & 18.2 \\
\hline & & 12 & 37.3 & 32.7 & 28.0 \\
\hline \multirow[t]{4}{*}{ Maduwang } & 350 & 1 & 6.6 & 5.8 & 4.9 \\
\hline & & 3 & 20.2 & 17.0 & 13.8 \\
\hline & & 6 & 33.4 & 28.1 & 22.8 \\
\hline & & 12 & 46.6 & 42.4 & 38.1 \\
\hline \multirow[t]{4}{*}{ Nanxi } & 802 & 1 & 47.5 & 25.9 & 4.3 \\
\hline & & 3 & 73.8 & 48.1 & 22.3 \\
\hline & & 6 & 81.4 & 63.1 & 44.8 \\
\hline & & 12 & 85.0 & 71.9 & 58.8 \\
\hline
\end{tabular}



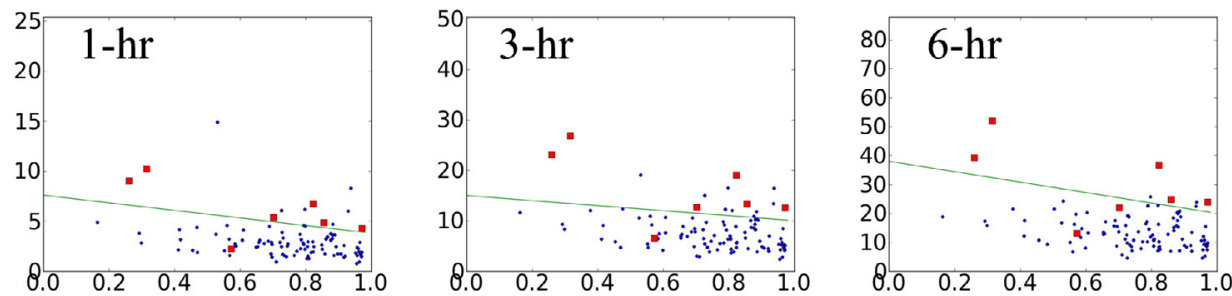

(e)
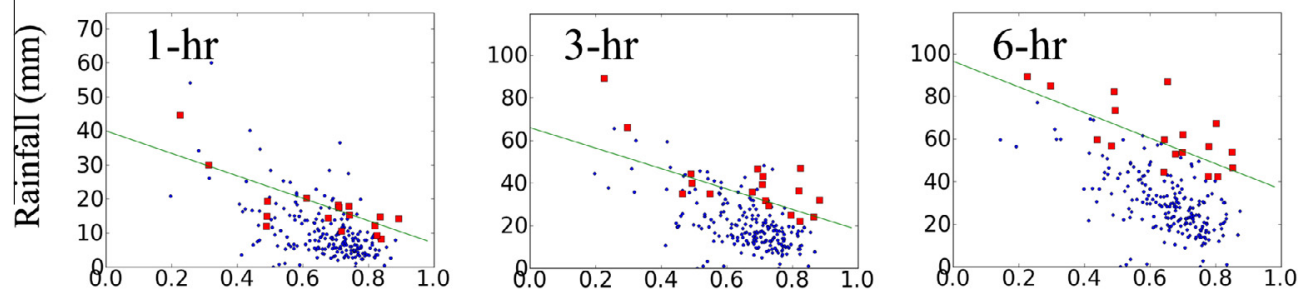

(f)
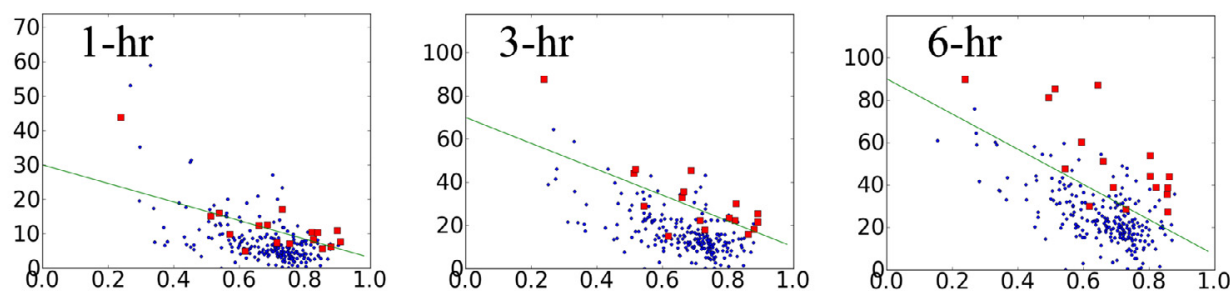
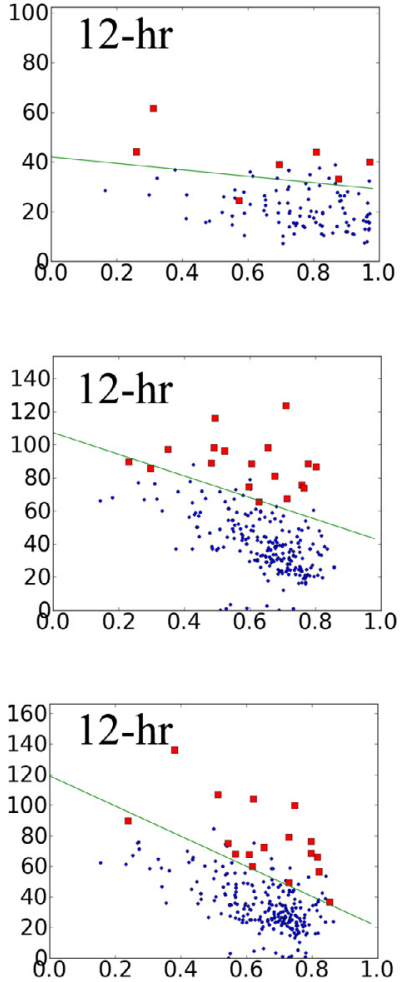

(g)

Soil Saturation

Fig. 6. Binary classification results of 1-, 3-, 6-, 12-h accumulation rainfall in three ungauged catchments: (e) Luolicun catchment; (f) Xiankeng catchment; (g) Aoxiaping catchment.

Finally, we constructed a contingency table by comparing the peak discharge in a flood event (with a time window of $12 \mathrm{~h}$ ) with the flooding threshold (calculated from the observed discharge) for both simulated and observed discharges and then calculated the accuracy indices to further assess the proposed method. The results are shown in Table $8 \mathrm{c}$. A comparison of the results in Table $8 \mathrm{~b}$ with those in Table $8 \mathrm{c}$ shows close performances between the forecasting method that was based on model simulations and the warning method that was based on rainfall thresholds. The warning method that was based on rainfall thresholds performed even better in some catchments: the CSI from the GBHM simulation in the semi-arid Zhidan catchment was 0.46 , slightly smaller than the CSI values from the rainfall threshold-based warning method (above 0.5 for all time spans). This result may be explained by the relatively poor model performance in the Zhidan catchments, as discussed in Section 5.1.

\subsection{Characteristics of the rainfall thresholds in different climate regions}

As shown in Fig. 5, the relationship between the initial soil moisture and the rainfall threshold varied significantly over these study catchments. The rainfall threshold in the humid region (Suichuan catchment) decreased significantly with increasing antecedent soil saturation (see Fig. 5 panel d) but decreased slightly with increasing soil moisture in the semi-humid and semi-arid regions (the other study catchments). The major reason for this difference can be explained as follows.

Runoff in humid regions is mainly generated from excess saturation. Neglecting evapotranspiration during rainfall, the runoff can be calculated as
$R=P-\left(W_{\max }-W_{\text {ini }}\right)=P-\left(\theta_{s}-\theta\right) \cdot d$,

where $R$ is the runoff, $P$ is the precipitation, $W_{\max }$ is the maximum soil water storage, $W_{\text {ini }}$ is the initial storage, $\theta$ is the initial soil moisture, $\theta_{S}$ is the saturated soil moisture, and $d$ is the soil depth. For a specific runoff (corresponding to the flooding threshold), the rainfall decreases linearly with decreasing soil moisture.

The soil depth in semi-arid regions, especially in the Loess Plateau, can reach several tens of meters, and excess infiltration dominates runoff generation, in which the runoff mainly depends upon the rainfall intensity and soil infiltration capacity. Semi-arid regions, whose soil exhibits small saturated hydraulic conductivity (approximately $10 \mathrm{~mm} / \mathrm{h}$ in the Loess Plateau) and soil-hardening compaction because of sparse vegetation, have low infiltration rates. The rainfall threshold in semi-arid regions is nearly constant because the infiltration rate tends to stabilize after a short time (less than $1 \mathrm{~h}$ ) and excess runoff occurs quickly.

These two distinct relationships between the rainfall threshold and soil moisture in different climate regions imply different strategies for use of the rainfall threshold. Application of the rainfall threshold for flash flood warning in humid regions requires dynamic estimating the soil moisture in real time, while we might use a constant rainfall threshold for a short time period in a small catchment in the semi-arid and semi-humid regions.

The indices in Table $8 \mathrm{~b}$ indicate that the 3-h and 6-h rainfall thresholds are more suitable, which is consistent with the results in Table 8a as explained in Section 5.2. Excess infiltration runoff plays a dominant role in semi-arid and semi-humid regions, and the rainfall intensity is more important than the accumulative rainfall. As shown in Table 8b, rainfall thresholds over short time spans $(3 \mathrm{~h})$ are more suitable for use in the Zhidan catchment 

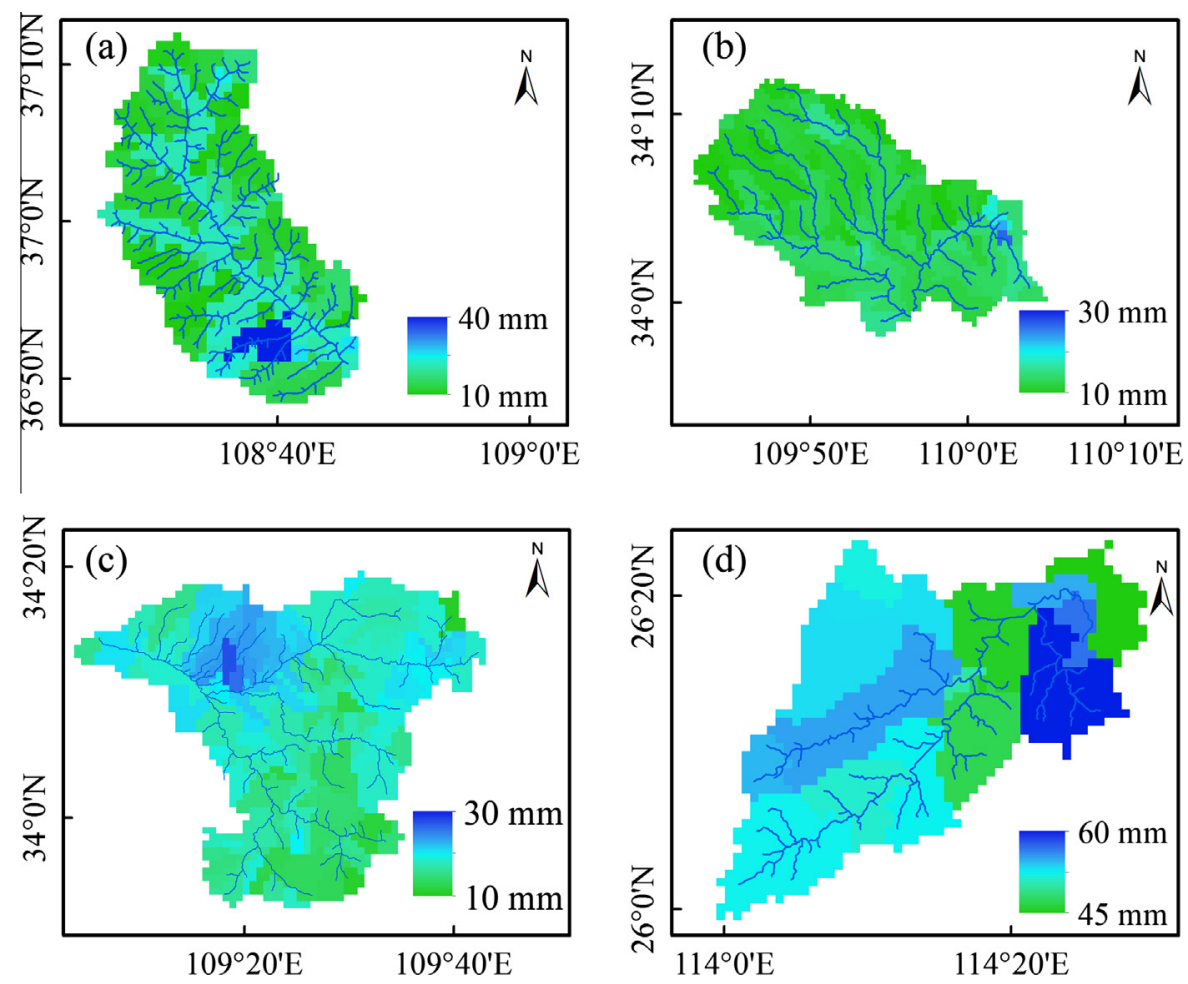

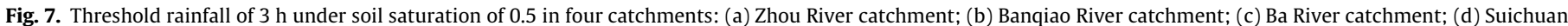
River catchment.

Table 8a

Accuracy of binary classification.

\begin{tabular}{|c|c|c|c|c|c|c|c|c|c|c|c|c|}
\hline \multirow[t]{2}{*}{ Station } & \multicolumn{3}{|l|}{$1 \mathrm{~h}$} & \multicolumn{3}{|l|}{$3 \mathrm{~h}$} & \multicolumn{3}{|l|}{$6 \mathrm{~h}$} & \multicolumn{3}{|l|}{$12 \mathrm{~h}$} \\
\hline & POD & FAR & CSI & POD & FAR & CSI & POD & FAR & CSI & POD & FAR & CSI \\
\hline Zhidan & 0.91 & 0.29 & 0.67 & 0.91 & 0.23 & 0.71 & 0.91 & 0.17 & 0.77 & 0.82 & 0.47 & 0.47 \\
\hline Banqiao & 0.71 & 0.60 & 0.34 & 0.71 & 0.44 & 0.45 & 0.64 & 0.44 & 0.43 & 0.79 & 0.48 & 0.46 \\
\hline Maduwang & 0.60 & 0.54 & 0.35 & 0.70 & 0.42 & 0.47 & 0.67 & 0.40 & 0.46 & 0.44 & 0.50 & 0.31 \\
\hline Nanxi & 0.56 & 0.64 & 0.28 & 0.67 & 0.25 & 0.55 & 0.89 & 0.27 & 0.67 & 0.89 & 0.43 & 0.53 \\
\hline
\end{tabular}

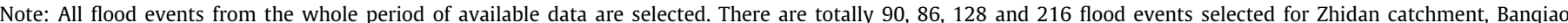
catchment, Maduwang catchment and Suichuan catchment respectively, among which, there are 11, 14, 10 and 9 flood events that exceeded the threshold flood.

Table 8b

Accuracy of flood warning based on the threshold rainfall.

\begin{tabular}{|c|c|c|c|c|c|c|c|c|c|c|c|c|}
\hline \multirow[t]{2}{*}{ Station } & \multicolumn{3}{|l|}{$1 \mathrm{~h}$} & \multicolumn{3}{|l|}{$3 \mathrm{~h}$} & \multicolumn{3}{|l|}{$6 \mathrm{~h}$} & \multicolumn{3}{|l|}{$12 \mathrm{~h}$} \\
\hline & POD & FAR & CSI & POD & FAR & CSI & POD & FAR & CSI & POD & FAR & CSI \\
\hline Zhidan & 0.60 & 0.18 & 0.53 & 0.53 & 0.11 & 0.50 & 0.53 & 0.11 & 0.50 & 0.56 & 0.10 & 0.53 \\
\hline Banqiao & 0.67 & 0.73 & 0.24 & 0.67 & 0.64 & 0.31 & 0.80 & 0.67 & 0.31 & 0.78 & 0.68 & 0.29 \\
\hline Maduwang & 0.50 & 0.00 & 0.50 & 0.75 & 0.45 & 0.46 & 0.92 & 0.37 & 0.60 & 0.92 & 0.25 & 0.71 \\
\hline Nanxi & 0.96 & 0.90 & 0.10 & 0.91 & 0.52 & 0.45 & 0.75 & 0.33 & 0.55 & 0.71 & 0.69 & 0.28 \\
\hline
\end{tabular}

Table 8c

Accuracy of flood warning based on real-time forecasting using distributed hydrological model (GBHM).

\begin{tabular}{llll}
\hline Station & POD & FAR & CSI \\
\hline Zhidan & 0.50 & 0.14 & 0.46 \\
Banqiao & 0.71 & 0.58 & 0.36 \\
Maduwang & 0.53 & 0.27 & 0.44 \\
Nanxi & 0.47 & 0.04 & 0.46 \\
\hline
\end{tabular}

and Banqiao catchment. The amount of accumulated rainfall in humid regions plays a more important role than the rainfall intensity, so the accumulative rainfall over a relatively long time span should be used as the rainfall threshold for flood warnings. Thus, rainfall thresholds over longer time spans $(6 \mathrm{~h})$ are more suitable for use in the Maduwang catchment and Nanxi catchment.

\subsection{Uncertainty in rainfall threshold estimation}

The uncertainties in the estimation of rainfall thresholds mainly originate from the uncertainties in model parameter estimation (such as the equifinality; Beven, 2006), the binary classification process, model structures, rainfall measurements and spatial interpolation, and climate and land use changes. The uncertainties from model parameter estimation and the binary classification process are discussed later. Only using gauge rainfall data with sparse temporal-spatial resolution for rainfall estimation may not 
Table 9a

Accuracy of flood warning based on the threshold rainfall for the ungauged interior catchments.

\begin{tabular}{|c|c|c|c|c|c|c|c|c|c|c|c|c|}
\hline \multirow[t]{2}{*}{ Station } & \multicolumn{3}{|l|}{$1 \mathrm{~h}$} & \multicolumn{3}{|l|}{$3 \mathrm{~h}$} & \multicolumn{3}{|l|}{$6 \mathrm{~h}$} & \multicolumn{3}{|l|}{$12 \mathrm{~h}$} \\
\hline & POD & FAR & CSI & POD & FAR & CSI & POD & FAR & CSI & POD & FAR & CSI \\
\hline Luolicun & 0.82 & 0.71 & 0.27 & 0.82 & 0.59 & 0.38 & 0.70 & 0.42 & 0.47 & 0.85 & 0.59 & 0.38 \\
\hline Xiankeng & 0.94 & 0.68 & 0.31 & 0.97 & 0.52 & 0.48 & 0.88 & 0.24 & 0.69 & 0.73 & 0.31 & 0.55 \\
\hline Aoxiaping & 0.82 & 0.64 & 0.34 & 0.85 & 0.51 & 0.45 & 0.92 & 0.45 & 0.52 & 0.81 & 0.43 & 0.5 \\
\hline
\end{tabular}

Table 9b

Accuracy of flood warning based on real-time forecasting using GBHM for the ungauged interior catchments.

\begin{tabular}{llll}
\hline Station & POD & FAR & CSI \\
\hline Luolicun & 0.50 & 0.40 & 0.38 \\
Xiankeng & 0.63 & 0.04 & 0.62 \\
Aoxiaping & 0.69 & 0.21 & 0.58 \\
\hline
\end{tabular}

Table 10

Accuracy of flood warning based on the threshold rainfall calculated using the simulation results from 1990 to 2002 .

\begin{tabular}{|c|c|c|c|c|c|c|c|}
\hline \multirow[t]{2}{*}{ Station } & \multicolumn{3}{|l|}{$3 \mathrm{~h}$} & \multicolumn{3}{|l|}{$6 \mathrm{~h}$} & \multirow{2}{*}{$\begin{array}{l}\text { Number of Evens that } \\
\text { exceed the threshold } \\
\text { flood }\end{array}$} \\
\hline & POD & FAR & CSI & POD & FAR & CSI & \\
\hline Nanxi & 0.89 & 0.60 & 0.38 & 0.75 & 0.45 & 0.46 & 3 \\
\hline
\end{tabular}

adequately represent the real conditions, especially at high altitudes (Daly et al., 2008). The spatial and temporal patterns of rainfall may also be important in triggering a flash flood. Lumping together all the temporal patterns of rainfall and using the average catchment-scale precipitation to determine the rainfall threshold may introduce uncertainty. These issues should be further discussed in future works.

We have evaluated the performance of the proposed method for flood warnings in four gauged catchments, but not in ungauged catchments. However, as stated before, most GBHM parameters are defined according to their physical meaning, either based on actual in situ measurements or regional/global databases, and only a few parameters must be calibrated in the gauged catchment and transferred to the ungauged catchment. Although the absolute value of a flood that is simulated by the hydrological model has error, we can assume that the model can properly simulate the relative magnitudes of flood peaks. Thus, the proposed approach for estimating the rainfall threshold in ungauged catchments should maintain reasonable accuracy. To prove this hypothesis, we treated two interior gauged sub-catchments in the Suichuan River catchment and one interior gauged sub-catchment in the Ba River catchment as ungauged catchments (see Fig. 1), with no calibration performed with the observed discharge; instead, we used the observed discharge data to evaluate the performance of the proposed method in the ungauged catchments. Because the two catchments are located in humid regions, we should pay more attention to the 6-h rainfall threshold as explained in Section 5.3. The CSI value for the gauged catchment (Nanxi station) was 0.55 (with a 6-h rainfall threshold, see Table $8 \mathrm{~b})$, while those for the interior ungauged catchment were 0.52 (Aoxiaoping station) and 0.69 (Xiankeng station), as shown in Table 9a. Therefore, the CSI maintained a high value in the interior 'ungauged' catchments. In the same vein, the CSI value in the Ba River catchment (located in a semi-humid region) was 0.6 (with a 6 -h rainfall threshold) in the gauged catchment (Maduwang station), while the CSI value in the ungauged catchment (Luolicun station) was 0.47. Comparing the accuracy of the flood warnings for the gauged catchments (Table 8c) and ungauged internal sub-catchment (Table 9b) based on real-time flood forecasting with GBHM demonstrates that the proposed method achieved very close accuracy in both the gauged and ungauged locations in the study areas. A small decrease in accuracy can be observed, which may have originated from degradation in the hydrological flood simulation by the hydrological model without calibration. However, this small decrease is reasonable and acceptable.

Uncertainty in binary classification is mainly caused by the sample size, which depends on the length of the available data records. The previous discussion regarding the Suichuan catchment was based on hydrological and meteorological data from 1951 to 2002. However, other study catchments do not possess such abundant data. We calculated the rainfall threshold for the Suichuan catchment by using simulation results from 1990 to 2002 (13 years) to evaluate the impact of the length of the data series on the accuracy of the rainfall threshold estimation. Then, we assessed the performance of the flood warnings based on this rainfall threshold by using all the available data. The evaluation results are shown in Table 10. The POD value did not show an obvious decrease upon shortening the length of the data records to 13 years, but the FAR value greatly increased and the CSI significantly decreased. We calculated the maximum one-hour and maximum 24-h accumulated and annual rainfalls in the periods of 1990-2002 and 1951-2002 to clarify whether changes in the rainfall climatology might result in this degradation. The results showed that only the maximum 24-h rainfall increased slightly during 1990-2002. This observation indicates that the increase in the FAR can be explained by higher classification error because of smaller sample numbers rather than to a change in the rainfall climatology. Nine flood events exceeded the flooding threshold (in terms of simulated discharge) in the Nanxi catchment during the entire period, but only 3 flood events exceeded this threshold from 1990 to 2002. As shown in Table 8a, in the entire study period, 11, 14, 10 and 9 flood events exceeded the flooding threshold in the Zhidan, Banqiao, Maduwang and Nanxi catchments, respectively. Thus, we suggest that more than approximately 10 flood events

Table 11

Cross-validation results for the accuracy of binary classification.

\begin{tabular}{|c|c|c|c|c|c|c|c|c|c|c|c|c|}
\hline \multirow[t]{2}{*}{ Station } & \multicolumn{3}{|l|}{$1 \mathrm{~h}$} & \multicolumn{3}{|l|}{$3 \mathrm{~h}$} & \multicolumn{3}{|l|}{$6 \mathrm{~h}$} & \multicolumn{3}{|l|}{$12 \mathrm{~h}$} \\
\hline & POD & FAR & CSI & POD & FAR & CSI & POD & FAR & CSI & POD & FAR & CSI \\
\hline Zhidan & 1.00 & 0.50 & 0.50 & 0.91 & 0.23 & 0.71 & 0.91 & 0.33 & 0.63 & 0.82 & 0.53 & 0.43 \\
\hline Banqiao & 0.86 & 0.73 & 0.26 & 0.79 & 0.68 & 0.30 & 0.71 & 0.55 & 0.38 & 0.79 & 0.52 & 0.42 \\
\hline Maduwang & 0.70 & 0.65 & 0.30 & 0.70 & 0.46 & 0.44 & 0.80 & 0.50 & 0.44 & 0.50 & 0.44 & 0.36 \\
\hline Nanxi & 0.56 & 0.72 & 0.23 & 0.56 & 0.38 & 0.42 & 0.67 & 0.40 & 0.46 & 0.89 & 0.50 & 0.47 \\
\hline
\end{tabular}


that exceed the flooding threshold are necessary to obtain good performance for the binary classification. Further analysis of the sample size (or data length) should be conducted by collecting more data in future research.

Cross-validation (developmental dataset containing events from $n-1$ years and verification dataset containing events from the remaining year) was performed to test the robustness of the binary classification; the results are shown in Table 11. Compared to the values in Table 8a, the CSI values decreased slightly, ranging from 0.30 to 0.71 . The accuracy of the binary classification slightly decreased, which indicates that the binary classification was reliable.

\section{Summary and conclusions}

This study employed a distributed hydrological model (GBHM) for flood simulation in four study catchments that were located in humid, semi-humid and semi-arid regions in China. We determined the flooding thresholds for warning through a frequency analysis according to the simulation results. Then, we introduced a method to determine the rainfall threshold for flash flood warning through a binary classification procedure. The method was applied to both gauged and ungauged sites in the study catchments and carefully evaluated across a number of catchments with a variety of climatic and hydrologic conditions. The major conclusions can be summarized as follows.

(1) The GBHM properly simulated flash floods in the four small study catchments, which were located in humid, semihumid and semi-arid regions in China. The GBHM also exhibited better performance in the humid area than in the semi-humid and semi-arid areas. This result may be explained by the low temporal resolution of the rainfall data, which is especially important for hydrologic simulation in arid areas, where excess infiltration runoff dominates.

(2) A frequency-based method was adopted to determine the flooding threshold for flash flood warning based on GBHMsimulated floods, which provided an approach to measure the flood severity in ungauged catchments. The rainfall threshold in both the gauged and ungauged catchments was derived from the binary classification approach and applied to pairs of the cumulative rainfall and degree of soil saturation for the simulated historical flood events. This method avoided running a hydrological model iteratively to determine the rainfall threshold, but only the soil saturation needed to be specified by continuously running the hydrological model or by other estimations such as in-situ observation.

(3) A comprehensive evaluation of the proposed warning method was carried out using three indices, namely, the POD, FAR and CSI. The results showed good performance from the proposed method: the CSI values of the binary classification ranged from 0.28 to 0.77 . Cross-validation in the study catchments also obtained high CSI values for the binary classification $(0.23$ to 0.71$)$. The CSI values of the warning method that was based on rainfall thresholds over different time spans in the four study catchments ranged from 0.10 to 0.71 . The warning method that was based on rainfall thresholds exhibited similar performance to the forecast method that was directly based on model simulation, which indicated the reliability of the proposed method. Evaluation in the interior sub-catchments showed that the proposed method achieved a good performance at uncalibrated locations in the study catchments, which demonstrated the method's applicability to ungauged catchments.
(4) The rainfall threshold exhibited high variability within each study catchment. The spatial variability of the rainfall threshold indicated that estimating the rainfall threshold over a small spatial scale was necessary to assist local flash flood warnings. Additionally, the rainfall threshold values decreased significantly with increasing initial soil moisture in the humid regions but decreased slightly in the semihumid and semi-arid regions. This result implies that application of the proposed rainfall threshold method in humid regions should carefully estimate and update the initial soil saturation either by running the hydrologic model or through in-situ observation. However, in the semi-humid and semi-arid regions, application of the rainfall threshold is not so sensitive to the initial soil saturation.

(5) The performance of the method was limited by the length of the available data records. The CSI value greatly decreased when the data length in the binary classification was shortened from 52 years to 13 years in the study area. In order to stabilize the performance of the proposed method, we suggest a reasonable data length contain approximately 10 flood events at least which exceed the flooding threshold.

Further research should focus on the influence of the spatial and temporal patterns of rainfall on the estimation of rainfall thresholds for flash flood warning.

\section{Acknowledgments}

This research was supported by the Ministry of Water Resources of the People's Republic of China and the Special Funds for the Commonwealth (project no. 201401008).

\section{References}

Alfieri, L., Salamon, P., Pappenberger, F., Wetterhall, F., Thielen, J., 2012. Operational early warning systems for water-related hazards in Europe. Environ. Sci. Policy $21,35-49$

Beven, K., 2006. A manifesto for the equifinality thesis. J. Hydrol. 320 (1-2SI), 18-36.

Blöschl, G., 2005. Rainfall-runoff modelling of ungauged catchments. In: Anderson, M.G.E. (Ed.), Encyclopedia of Hydrological Sciences. John Wiley \& Sons, Chichester, pp. 2061-2080.

Borga, M., Boscolo, P., Zanon, F., Sangati, M., 2007. Hydrometeorological analysis of the 29 August 2003 flash flood in the Eastern Italian Alps. J. Hydrometeorol. 8 (5), 1049-1067.

Cannon, S.H., Gartner, J.E., Wilson, R.C., Bowers, J.C., Laber, J.L., 2008. Storm rainfall conditions for floods and debris flows from recently burned areas in southwestern Colorado and southern California. Geomorphology 96 (3-4), 250-269.

Clark, R.A., Gourley, J.J., Flamig, Z.L., Hong, Y., Clark, E., 2014. CONUS-wide evaluation of national weather service flash flood guidance products. Weather Forecasting 29 (2), 377-392.

Dai, Y., Shangguan, W., Duan, Q., Liu, B., Fu, S., Niu, G., 2013. Development of a China dataset of soil hydraulic parameters using pedotransfer functions for land surface modeling. J. Hydrometeorol. http://dx.doi.org/10.1175/JHM-D-120149.1.

Daly, C., Halbleib, M., Smith, J.I., et al., 2008. Physiographically sensitive mapping of climatological temperature and precipitation across the conterminous United States. Int. J. Climatol. 28 (15), 2031-2064.

Duan, Y.H., 2010. Problems and think in dam system construction in Zhidan County. Shanxi Water Resour., 01:96+95 (in Chinese)

Gourley, J.J., Erlingis, J.M., Hong, Y., Wells, E.B., 2012. Evaluation of tools used for monitoring and forecasting flash floods in the United States. Weather Forecasting 27 (1), 158-173.

Hou, T., Kong, F., Chen, X., Lei, H., 2013. Impact of 3DVAR data assimilation on the prediction of heavy rainfall over Southern China. Adv. Meteorol. 129642

Javelle, P., Fouchier, C., Arnaud, P., Lavabre, J., 2010. Flash flood warning at ungauged locations using radar rainfall and antecedent soil moisture estimations. J. Hydrol. 394 (1-2SI), 267-274.

Kendall, M., 1975. Rank Correlation Methods, fourth ed. Charles Griffin, p. 202.

Li, Z.J., Jiang, T.T., Huang, P.N., et al., 2015. Analysis of impact of Rainfall and topography to hydrological model simulation. Adv. Water Sci. 04, 473-480 (in Chinese).

Liu, Zhiyu, 2009. Progress and prospect of flood forecast technology research in China. China Flood Drought Manage. 05, 13-16 (in Chinese).

Mann, H.B., 1945. Nonparametric test against trend. Econometrica 13 (3), 245-259. 
Martina, M.L.V., Todini, E., Libralon, A., 2006. A Bayesian decision approach to rainfall thresholds based flood warning. Hydrol. Earth Syst. Sci. 10 (3), 413-426.

Mogil, H.M., Monro, J.C., Groper, H.S., 1978. NWS flash flood warning and disaster preparedness programs. Bull. Am. Meteorol. Soc. 59 (6), 690-699.

Morris, D.G., 1975. Use of a multi-zone hydrologic model with distributed rainfall and distributed parameters in national weather service river forecast system. Bull. Am. Meteorol. Soc. 56 (12), 1326-1326.

New, M., Hulme, M., Jones, P., 2000. Representing twentieth-century space-time climate variability. Part II: Development of 1901-96 monthly grids of terrestrial surface climate. J. Clim. 13 (13), 2217-2238.

Norbiato, D., Borga, M., Esposti, S.D., Gaume, E., Anquetin, S., 2008. Flash flood warning based on rainfall thresholds and soil moisture conditions: an assessment for gauged and ungauged basins. J. Hydrol. 362 (3-4), 274-290.

Norbiato, D., Borga, M., Dinale, R., 2009. Flash flood warning in ungauged basins by use of the flash flood guidance and model-based runoff thresholds. Meteorol. Appl. 16 (1), 65-75.

Ntelekos, A.A., Krajewski, W.F., Georgakakos, K.P., 2006. On the uncertainties of flash flood guidance: towards probabilistic forecasting of flash floods. J. Hydrometeorol. 7, 896-915.

Penman, H.L., 1948. Natural evaporation from open water, bare soil and grass. Proc. R. Soc. Lond. A 193 (1032), 120-145.

Reed, S., Schaake, J., Zhang, Z., 2007. A distributed hydrologic model and threshold frequency-based method for flash flood forecasting at ungauged locations. J. Hydrol. 337 (3-4), 402-420.

Refsgaard, J.C., Knudsen, J., 1996. Operational validation and intercomparison of different types of hydrological models. Water Resour. Res. 32 (7), 2189-2202.

Schaefer, J.T., 1990. The critical success index as an indicator of warning skill. Weather and Forecasting 5, 570-575.

Schmidt, J.A., Anderson, A.J., Paul, J.H., 2007. Spatially-variable, physically-derived flash flood guidance. In: Paper 6B.2, Proceedings of the 21st Conference on Hydrology, 87th Meeting of the AMS, San Antonio, Texas, Jan 15-18.

Seo, Dugwon, Lakhankar, Tarendra, Mejia, Juan, Cosgrove, Brian, Khanbilvardi, Reza, 2013. Evaluation of operational national weather service gridded flash flood guidance over the Arkansas red river basin. J. Am. Water Resour. Assoc. 6 (49), 1296-1307.

Shen, Y., Pan, Y., Yu, J.J., Zhao, P., Zhou, Z.J., 2013. Quality assessment of hourly merged precipitation product over China. Trans. Atmos. Sci. 36 (1), 37-46 (in Chinese).

Wang, Z.Y., 2011. Practice and suggestions of the dam system construction in Zhidan County. Shaanxi Water Resour. 02, 168-169 (in Chinese).

Widrow, B., Hoff, M.E., 1960. Adaptive switching circuits. In: Proc. Of WESCON Conv. Rec., part 4, pp. 96-140.

Yang, D.W., Herath, S., Musiake, K., 1998. Development of a geomorphology-based hydrological model for large catchments. Annu. J. Hydraul. Eng. 42, 169-174.

Yang, D., Herath, S., Musiake, K., 2001. Spatial resolution sensitivity of catchment geomorphologic properties and the effect on hydrological simulation. Hydrol. Process. 15, 2085-2099.

Yang, D., Herath, S., Musiake, K., 2002. A Hillslope-based hydrological model using catchment area and width functions. Hydrol. Sci. J. 47 (1), 49-65.

Yang, D.W., Koike, T., Tanizawa, H., 2004. Application of a distributed hydrologica model and weather radar observations for flood management in the upper Tone River of Japan. Hydrol. Process. 18, 3119-3132. http://dx.doi.org/10.1002 hyp.5752.

Yang, D.W., Gao, B., Jiao, Y., Lei, H.M., Zhang, Y.L., Yang, H.B., Cong, Z.T., 2015. A distributed scheme developed for eco-hydrological modeling in the upper Heihe River. Sci. China: Earth Sci. 58, 36-45. http://dx.doi.org/10.1007/s11430014-5029-7.

Younis, J., Anquetin, S., Thielen, J., 2008. The benefit of high-resolution operational weather forecasts for flash flood warning. Hydrol. Earth Syst. Sci. 12 (4), 10391051.

Zhang, H.P., 2013. Study on the flood risk management and technology of the small mountain watershed. China Institute of Water Resources \& Hydropower Research, Beijing, pp. 1-4 (in Chinese).

Zhu, J., Kong, F., Lei, H., 2013. A regional ensemble forecast system for stratiform precipitation events in the Northern China Region. Part II: Seasonal evaluation for summer 2010. Adv. Atmos. Sci. 30 (1), 15-28. 